\title{
State-of-the-Art Measurement Instrumentation and Most Recent Measurement Techniques for Parabolic Trough Collector Fields
}

\author{
Alex Brenner ${ }^{1, *(\mathbb{D}}$, Tobias Hirsch ${ }^{1}\left(\mathbb{D}\right.$, Marc Röger $^{2}\left(\mathbb{D}\right.$ and Robert Pitz-Paal ${ }^{3}$ \\ 1 German Aerospace Center (DLR), Institute of Solar Research, Wankelstrasse 5, 70563 Stuttgart, Germany; \\ tobias.hirsch@dlr.de \\ 2 German Aerospace Center (DLR), Institute of Solar Research, Paseo de Almería 73, \\ E-04001 Almería, Spain; marc.roeger@dlr.de \\ 3 German Aerospace Center (DLR), Institute of Solar Research, Linder Höhe, 51147 Cologne, Germany; \\ robert.pitz-paal@dlr.de \\ * Correspondence: alex.brenner@dlr.de
}

check for updates

Citation: Brenner, A.; Hirsch, T.; Röger, M.; Pitz-Paal, R.

State-of-the-Art Measurement Instrumentation and Most Recent Measurement Techniques for Parabolic Trough Collector Fields Energies 2021, 14, 7166. https:// doi.org/10.3390/en14217166

Academic Editors: Andrea Giostri and Marco Binotti

Received: 13 September 2021

Accepted: 25 October 2021

Published: 1 November 2021

Publisher's Note: MDPI stays neutral with regard to jurisdictional claims in published maps and institutional affiliations.

Copyright: (c) 2021 by the authors. Licensee MDPI, Basel, Switzerland. This article is an open access article distributed under the terms and conditions of the Creative Commons Attribution (CC BY) license (https:/ / creativecommons.org/licenses/by/ $4.0 /)$.

\begin{abstract}
The presented review gives reliable information about the currently used measurement instrumentation in parabolic trough fields and recent monitoring approaches. The usually built-in measurement equipment in the solar field, clamp-on systems for flexible measurements of temperature and flow, solar irradiance measurements, standard meteorological equipment, laboratory devices for heat transfer fluid analyses and instruments related to the tracking of solar collector assemblies are presented in detail. The measurement systems are reported with their measurement uncertainty, approximate costs and usual installation location for the built-in instrumentation. Specific findings related to the installation and operation of the measurement devices are presented. The usually installed instrumentation delivers a lot of measurements all over the field at the expense of measurement accuracy, compared to special test facility equipment. Recently introduced measurement approaches can improve the standard instrumentation in terms of accuracy, frequency, spatial distribution or can even extend the amount of measurands. The information about available measurands is the basis for future operation and maintenance solutions based on data-driven approaches.
\end{abstract}

Keywords: concentrating solar power; measurement instrumentation; sensor; parabolic trough; condition monitoring; measurement uncertainties

\section{Introduction}

With the ongoing discussion of climate change and the shift toward electric mobility, renewable energy sources are more in the focus than ever before. An established source of renewable energy with the capability to deliver dispatchable electricity is concentrated solar power (CSP). There is a variety of different types of CSP plants, which can be categorized according to their focus type into point focus and line focus designs. Solar towers and parabolic dish systems correspond to the first group, whereas linear Fresnel and parabolic trough plants are line focus designs. Today, over 6.2 GW of CSP plants are operating, whereas parabolic troughs have the largest share [1]. The importance of monitoring is increasing with the number of plants. Most of these plants are in the power range of about 50 to $150 \mathrm{MW}$ and can be divided into the following functional units: solar field, thermal storage and power block, see Figure 1. The solar field collects energy in the form of thermal energy in a heat transfer fluid (HTF). The power block converts the thermal energy into electric energy. The power block is comparable to conventional Rankine cycle power plants. This also holds for its measurement equipment. Thus, the focus for this publication is on the solar field. A solar field able to deliver thermal power of about $250 \mathrm{MW}$ has a spatial extension of about $1.5 \times 1.5 \mathrm{~km}^{2}$. At this size, the solar field is typically divided into four subfields, connected via cold and hot header pipes to the power block, see Figure 1 bottom 
right. The color gradient from blue to red shows the heating of the HTF in each loop. The complete solar field usually consists of over 150 collector loops with four to six collectors per loop. The measurement equipment in the solar field is installed in every collector of every loop. In addition, there is measurement equipment for every subfield. This setup leads to approx. 2000 measurement channels required for an entire field.

Collector side view

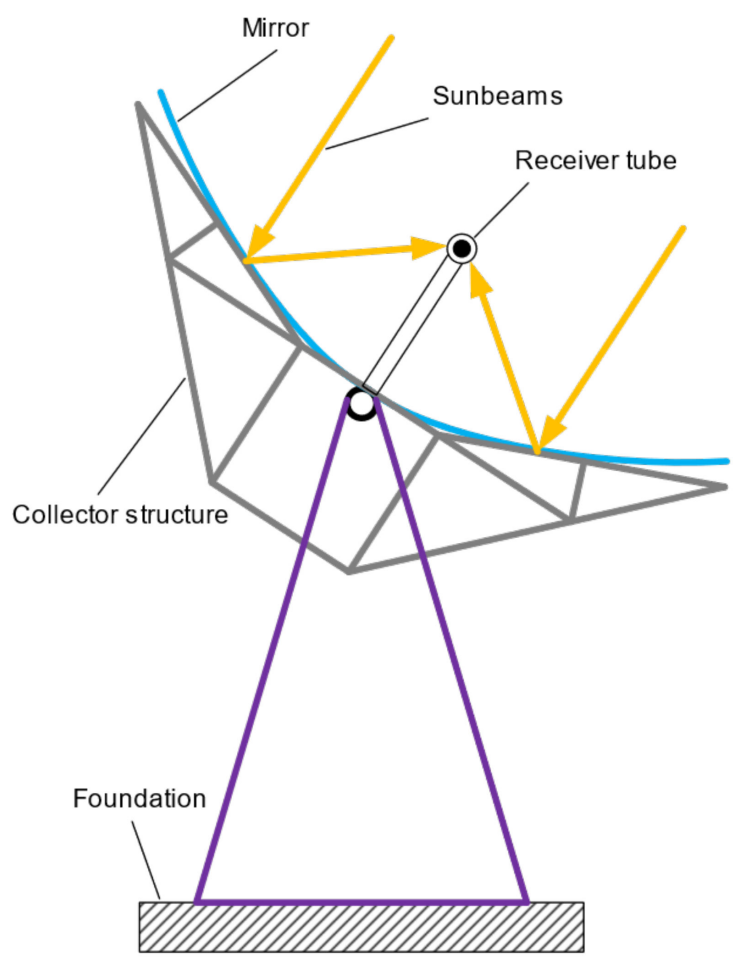

Solar collector assembly front view

Solar collector assembly (SCA)
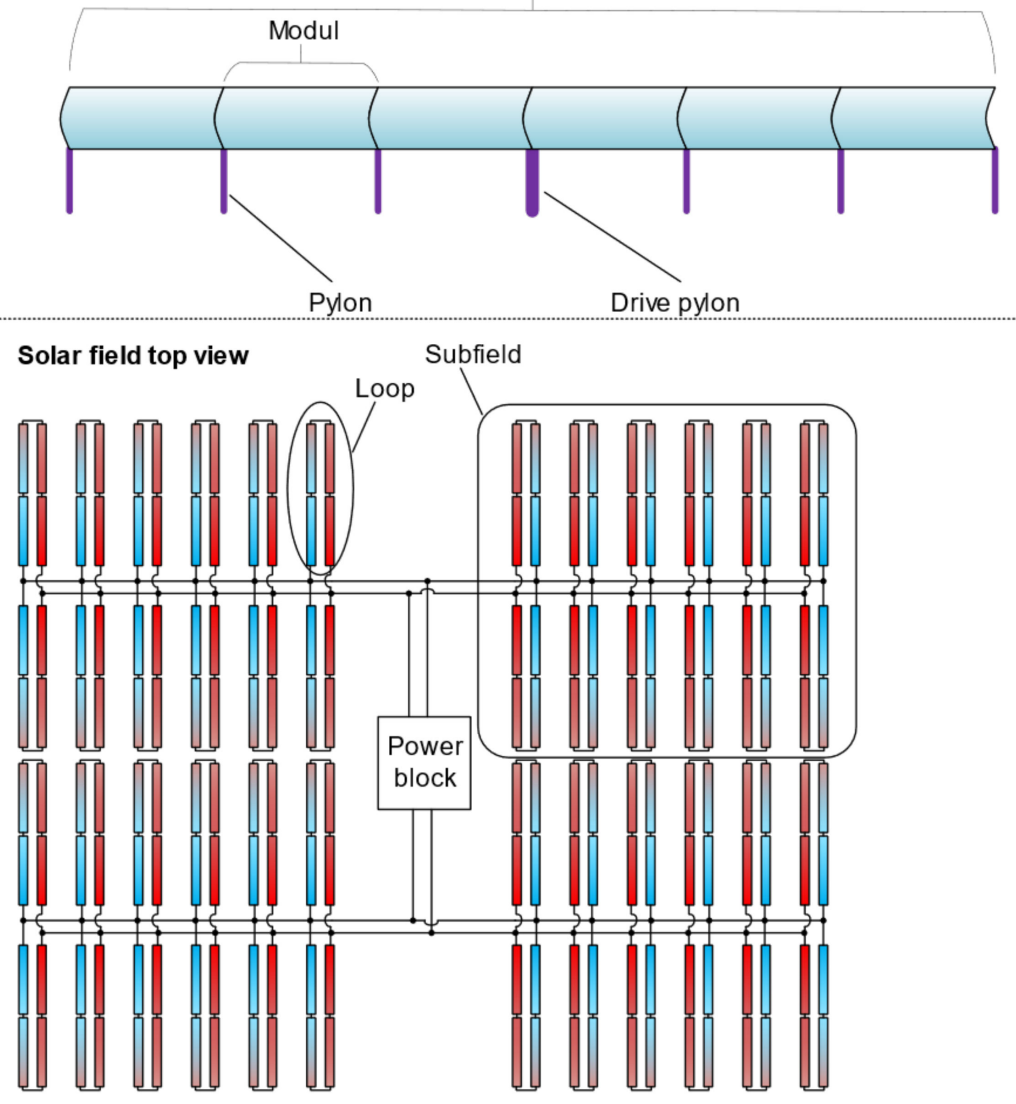

Figure 1. Parabolic trough overview, single collector structure in side view (left), solar collector assembly in front view (top right), whole solar field with typical H-layout in top view (bottom right).

Present solar power plants are equipped with a variety of different measurement sensors. Currently, the sensors are mainly used to deliver input data for a certain control task in the field. Trends for improved solar field operation, such as process monitoring and process optimization, assign the sensors an additional task. The reason for this is that the operators are forced to deliver electricity at constantly decreasing market prices. The 2030 cost target of the US department of energy (DOE) emphasizes this trend with a levelized cost of electricity (LCOE) for baseload CSP of USD 0.05/ $\mathrm{kWh}$ [2]. As a consequence, the operators need to maximize the efficiency of their plants. Artificial intelligence (AI) approaches for monitoring and optimization are one of the biggest trends for yield maximization. These big data approaches usually use the already implemented measurement instrumentation as a basis. This helps to keep the costs as low as possible and maximizes the benefits from improved operation strategies. As a result, knowledge about the strengths and weaknesses of current measurement instrumentation is crucial for the development and implementation of big data techniques. In the current literature, there is no comprehensive summary on the built-in instrumentation and no overview on recent measurement approaches. This presented review paper tries to fill this gap and concentrates on the following questions: 
(Section 2) What measurement equipment is usually installed in the fields? (Tables 1-4) What is the accuracy of the used instrumentation? (Section 2.2) Where are the instruments located in the field? (Section 3) How can new approaches change solar field monitoring?

\section{State of the Art Measurement Equipment}

In the following paragraph, the built-in measurement equipment in a parabolic trough collector field is presented. This section covers a broad variety of plant layouts typical for today's CSP projects. The first, Section 2.1, introduces the measurement equipment for gathering the most important measurands in the solar field. It includes a table for comparing the measurand, the used measuring device, the expected accuracy and a rough estimation of the overall costs for in-field installation. Section 2.2 gives an overview on the location of the used measurement instrumentations.

The information compiled in this chapter is based on literature references, on unpublished material available to the authors and personal experience from cooperation with the respective industry. It, thus, reflects the best available information to the authors.

\subsection{Measurement Equipment Characteristics}

Most of the measurement devices in parabolic trough fields are standard industry measurement equipment. Table 1 presents the recorded measurands, the commonly used equipment and its accuracy. The table is completed by a cost indication. This is important to consider when designing new process monitoring concepts, if an additional measurement instrumentation is required.

Measurement systems usually consist of multiple separate elements. The first element is the sensor. The signal can be transformed, amplified, transmitted and digitized afterwards. Every part of this measurement chain is prone to error. The term transducer describes the combination of a sensor and a conversion element, the term transmitter stands for a transducer and signal processing, see Figure 2 [3].

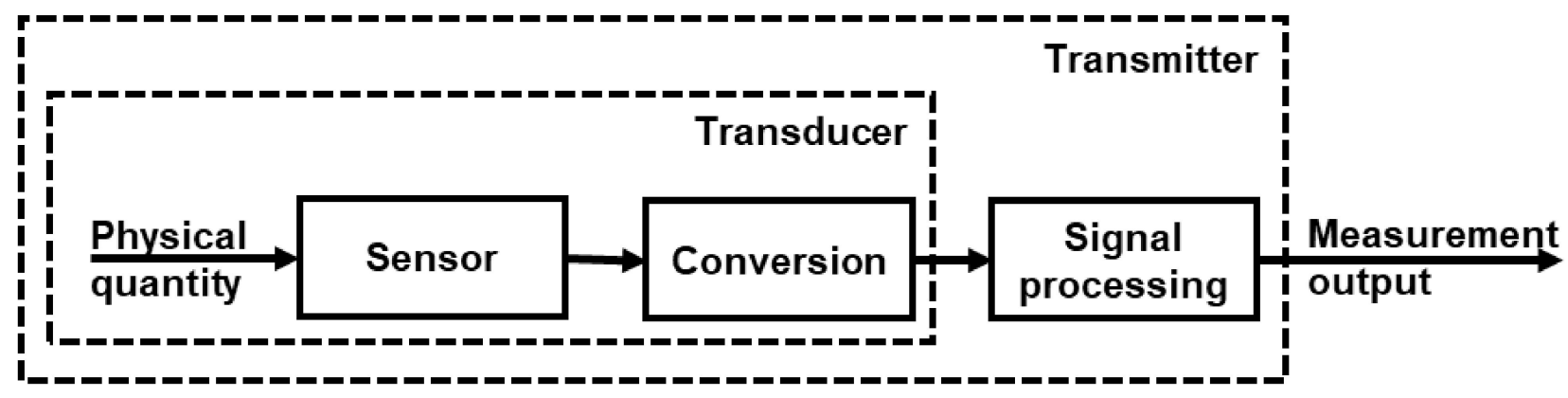

Figure 2. Measurement chain from sensor to measurement output.

If corresponding literature was found, the accuracy of the measurands is given as the overall accuracy of the whole measurement chain. Otherwise, only the accuracy of the sensor itself is listed, since it is presumed that the sensor has the highest influence on the overall uncertainty. An important point to mention is the trade-off between cost and accuracy, which is always present in the built-in instrumentation, as well as in the measurement instrumentation for test facilities. Every built-in measurement system fulfills a certain task in the solar field, usually a control task. Therefore, the numerous built-in measurement systems might primarily be chosen by the lowest possible cost and secondly by the achievable accuracy. In test facilities with higher requirements on accuracy and a lower number of sensors, the costs are less important and accuracy requirements are dominant.

The costs for the sensor implementation in the solar field can be divided into sensor costs and implementation costs. The sensor costs for different measurands vary a lot, e.g., between a few euros for a thermocouple and thousands of euros for a Coriolis flow meter. The implementation costs depend mostly on the location of the sensor in the field, e.g., if special construction works and cabling are needed to connect the sensor to field 
cabinets and finally to the central control station, the costs are much higher. The cost for the software licenses and software implementation in the control room is a significant factor in the overall implementation cost. Every implementation task needs staff, and the wages differ much from country to country. In order to enable a comparison of the different measurement instrumentation, only the approximate transmitter cost is listed in the following tables. The rules of thumb from process engineering show that an average total cost for the control system is $\sim$ EUR 2000 per solar collector assembly (SCA). Local control and superordinate field control have almost the same share in the total costs. Installing measurement instrumentation after commissioning is usually very expensive and, therefore, not recommended. Dependent on the sensor type and the foreseen infrastructure, the costs for subsequently installed instrumentation can vary between hundreds of euros and tens of thousands of euros.

\subsubsection{Uncertainty Measures}

As far as possible, the uncertainty $u$ of the measurements is given in combined standard uncertainties, indicated with index $c\left(u_{\mathrm{c}}(y)\right)$, according to the Guide to the expression of uncertainty in measurement (GUM) [4]. The standard uncertainty is the "uncertainty of the result of a measurement expressed as a standard uncertainty" [4]. The combination of uncertainties can be further divided into the case of uncorrelated and correlated input quantities. If two or more input quantities are related, the correlated case is relevant. If not explicitly stated, the input quantities are assumed to be uncorrelated in the following. The combined standard uncertainty can then be calculated with the functional relationship $f$ of the input quantities according to Equation (1). The combination of uncertainties is needed for the calculation of the uncertainty budgets from the measurement chain, e.g., resistance temperature measurement from sensing element to measurement output in ${ }^{\circ} \mathrm{C}$, as well as for the calculation of a target quantity based on other measurements, e.g., mass flow calculated from volumetric flow and temperature dependent fluid density. Within the GUM, the standard uncertainty can be evaluated with Type A, which is based on knowledge from repeated measurements. That means the standard uncertainty is given by a "probability density function" from an "observed frequency distribution" [4]. The Type B evaluation is based on previous measurements, experience with materials and instruments, manufacturer's specifications, data from calibration and uncertainties assigned to reference data from handbooks. That means the standard uncertainty is given by all the available information describing the variability of an input quantity [4]. The appropriate use of the given information requires experience and knowledge about the underlying physical effects. Type B evaluations are needed since a laboratory has limited time and resources for an exhaustive statistical investigation of the causes of uncertainties.

$$
u_{\mathrm{c}}^{2}(y)=\sum_{i=1}^{N}\left(\frac{\partial f}{d x_{\mathrm{i}}}\right)^{2} u^{2}\left(x_{\mathrm{i}}\right)
$$

The expanded uncertainty, with capital letter $U$, is defined by multiplying $u_{\mathrm{c}}(y)$ by a coverage factor, $k$. Within this publication, the coverage factor is $k=2$ or, in another notation, $2 \sigma$. This coverage factor, together with a normal distribution, has a level of confidence of approx. $95 \%$ for the result of the measurement.

\subsubsection{Temperature Sensors}

The first group of sensors are HTF temperature measuring devices that represent the majority of the temperature measurements in the solar field. The common practice for installing HTF temperature instrumentation within the field is a wetted integration of the sensor with an open thermowell or an embedded installation with a closed thermowell, see Figure 3. The wetted type has better contact to the fluid and provides more accurate measurements and a faster response time than the embedded type. However, the wetted type has a higher risk of leakage due to the direct fluid contact. The operating pressure 
and the corrosiveness of the fluid limit the installation with open thermowells [5]. The replacement of a wetted sensor requires depressurization or draining of the corresponding pipe section and, therefore, leads to a system downtime. The material of the sensing probe might not be resistive against corrosion in plants with molten salt HTFs [6]. Closed thermowells, therefore, protect the sensing element in such aggressive environments. The sensor location can influence the measurement error significantly higher than the error tolerance given by the instrument's manufacturer [5,7].

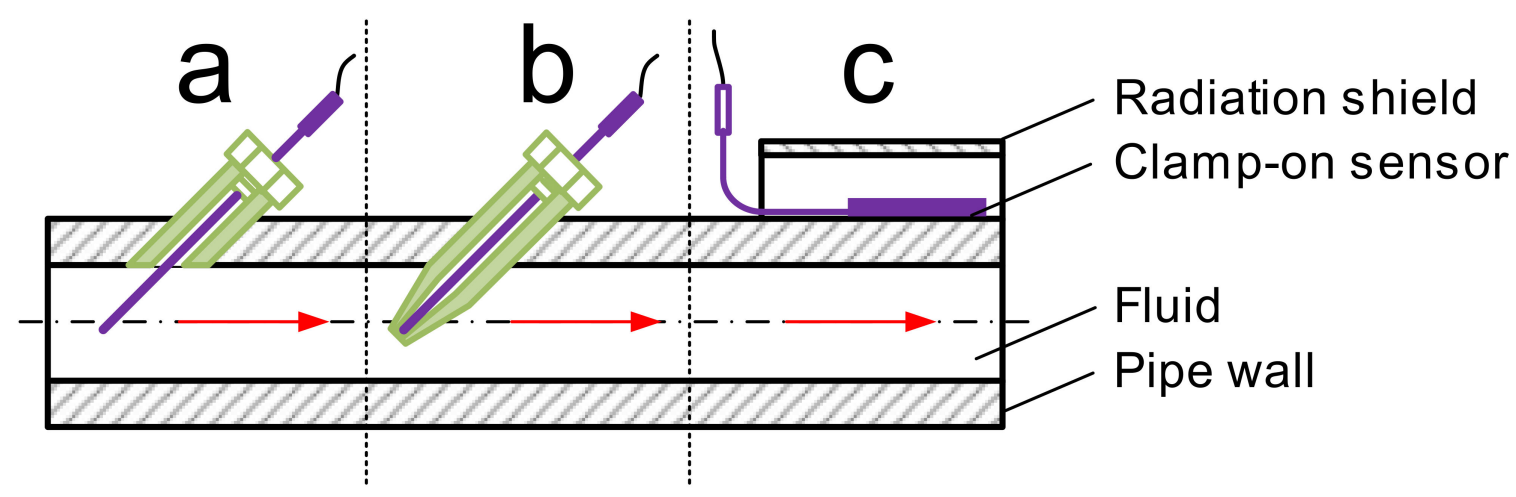

Figure 3. Temperature sensor installations shown without insulation, (a) wetted integration, (b) embedded installation, (c) clamp-on sensor, figure inspired by [7].

Besides the permanently installed temperature sensors, clamp-on sensors are often used for temporally limited, special measurement events such as the recalibration of existing sensors, performance and acceptance testing or troubleshooting during operation [7]. They have the advantage of being highly flexible and the HTF cycle stays unaffected. The clamp-on sensors are located on the outside of the pipe and measure the pipe temperature at this position, see Figure 3. To determine the HTF temperature, a correction function has to be applied. In the case of Nouri et al. [7], a polynomial correction function from experimental data with typical solar field parameters was carried out. In addition, a correction via dimensional analysis for more general applications was performed. In order to maintain turbulent flow for the application of clamp-on temperature devices, the Reynolds number $(R e)$ needs to be kept in temperature dependent limits. For typical loop-inlet and -outlet temperatures for thermal oil solar fields $\left(T_{\text {in }} \approx 300{ }^{\circ} \mathrm{C}, T_{\text {out }} \approx 390{ }^{\circ} \mathrm{C}\right)$, the limits are $\operatorname{Re}\left(T_{\text {in }}\right)=1.5 \times 10^{5}$ and $\operatorname{Re}\left(T_{\text {out }}\right)=2 \times 10^{5}$ [7]. For a correct attachment, the pipe insulation needs to be removed to place the sensor on the bare tube. Insulation and a shield may be applied to minimize heat losses to the environment. Clamp-on devices as well as permanently installed temperature measurement instrumentation usually include a Pt-100 sensor [8] or a thermocouple [9], with different sensor classes according to the requirements of the measurement. Pt-100 stands for a resistance temperature device with platinum as the sensor material and nominal resistance of $100 \Omega$ at $0{ }^{\circ} \mathrm{C}$. With higher temperatures, the resistance rises non-linearly with approx. $0.385 \Omega /{ }^{\circ} \mathrm{C}$ [3]. The resistance thermometers are classified according to their accuracies and temperature ranges in class AA, A, B, or C [8], where AA is the class with the highest accuracy, but lowest operating temperature. For class $B$, some manufacturers defined the extended tolerance classes as $1 / 3,1 / 5$ or $1 / 10$ with reduced deviations. With higher temperatures, the uncertainties from the sensor rise. For Pt-100 Type A, the permissible deviation is $\pm(0.15+0.002 \times \mathrm{T})$; for $1 / 10$ Type $B, \pm 1 / 10$ $(0.3+0.005 \times \mathrm{T})$ is allowable [8]. Therefore, the temperature of the uncertainty evaluation is stated as well in Table 1 . The temperatures are typical loop inlet $T_{\text {in }}$ and outlet $T_{\text {out }}$ set point temperatures for a thermal oil solar field loop. Thermocouples are pairs of metals connected in a closed circuit. Due to the thermoelectric effect, a temperature-dependent electromotive force in the form of an electric voltage can be measured. According to the combination of materials, the thermocouples have different measuring ranges, sensitivities and accuracies. The types are named with different letters. The often-used type $\mathrm{K}$ 
thermocouples have a measurement sensitivity of approx. $41 \mu \mathrm{V} /{ }^{\circ} \mathrm{C}$ [3]. With higher temperatures, the uncertainties from the sensor rise. For type $\mathrm{K}$, class one thermocouples, the permissible deviation is $\pm 1.5^{\circ} \mathrm{C}$ or $\pm(0.004 \times \mathrm{T})$ [9]. For class two, $\pm 2.5^{\circ} \mathrm{C}$ or $\pm(0.0075 \times \mathrm{T})$ is allowable [9]. In both cases, the higher value is valid.

The accuracy of both sensors is, in the first place, a result of the measurement principle and, secondly, depends on the sensor class [10]. Roughly speaking, for highly precise measurements, the Pt-100 type is used, whereas thermocouples are applied for less demanding measurements. In general, the accuracy of a measurement can be improved by calibrating the sensor. For calibration, the thermometer is placed in a temperature-controlled environment together with a reference instrument, whose calibration is traceable to reference standards [3]. These reference standards are defined by the triple points, melting points or freezing points of selected substances. With this calibration procedure, the offset from the instrument to standard specifications can be quantified. However, it is often found in practice that sensors are calibrated during installation, but no re-calibration is carried out during the operation time of the plant. All the measured sensor values are influenced by drift over time. The rate can vary due to drift impact factors in the HTF environment (e.g., high temperatures, high temperature gradients, long operating duration, mechanical or chemical impacts). Thermal or mechanical stresses can lead to permanent changes in the sensor material. Chemical impacts can lead to contamination of the sensor material and therefore, slightly change the electrical properties of the material. Besides the sensor element itself, changes due to corrosion in the cabling can also lead to drifts in the temperature signal. This leads to a general decrease in the measurement accuracy over time [11]. A re-calibration should be carried out according to the needs of measurement accuracy and the occurrence frequency of the mentioned drift impact factors [11]. For yield measurements and test facilities, a re-calibration should be carried out at least every two years, if reliable measurements are needed. The sensors should be calibrated at a temperature level that corresponds to the temperatures during operation. Fixed installations of process instruments make re-calibrations difficult. In this case, the instruments may be calibrated in their operation position with a reference instrument [3]. In contrast to the recommended operation time between calibrations, the built-in sensors often stay in the field until they fail without being re-calibrated [12]. An example for mechanical induced drift is given in [7]. In this context, Nouri et al. [7] found out that the bending of a Pt-100 sensor sheath can lead to an underestimation of the temperature of about $0.2 \mathrm{~K}$ at $400{ }^{\circ} \mathrm{C}$. In this case, a re-calibration is recommended. In summary, the common practice of re-calibration differs a lot from the recommended procedure. This opens potential for improvement for more accurate measurements without a change in the instrumentation itself.

In the application of parabolic trough plants, temperature transducers with uncertainties of up to $1 \%$ of the measured value are acceptable. The savings from using cheaper transducers with a higher uncertainty does not compensate the problems that can occur in the system control, e.g., stabilizing the loop outlet temperature. For yield measurements and test facilities, higher accuracies are needed. These can be achieved with the choice of a Pt-100 thermometer and a sensor class corresponding to the temperature range and accuracy requirements. Frequent re-calibration, depending on the instrument's operating environment, is necessary to maintain the accuracy of the transducer.

\subsubsection{Mass and Volume Flow Meters}

The second group are flow meters, which can be divided according to the measurement principle into volumetric flow meters and mass flow meters. In most of the applications, the interesting quantity is the mass flow. If the flow is measured via volumetric flow meters, the corresponding mass flow has to be calculated by means of the fluid density. The density mainly depends on the temperature. Many devices are, therefore, equipped with an additional temperature sensor. Measurement uncertainty values thus consider the additional uncertainty originating from the conversion from volumetric to mass flow. This includes the uncertainty for temperature measurement and temperature-density 
correlations [12]. The volumetric flow meters used in parabolic trough field applications are vortex, ultrasonic and pressure-drop flow meters, see Figure 4.

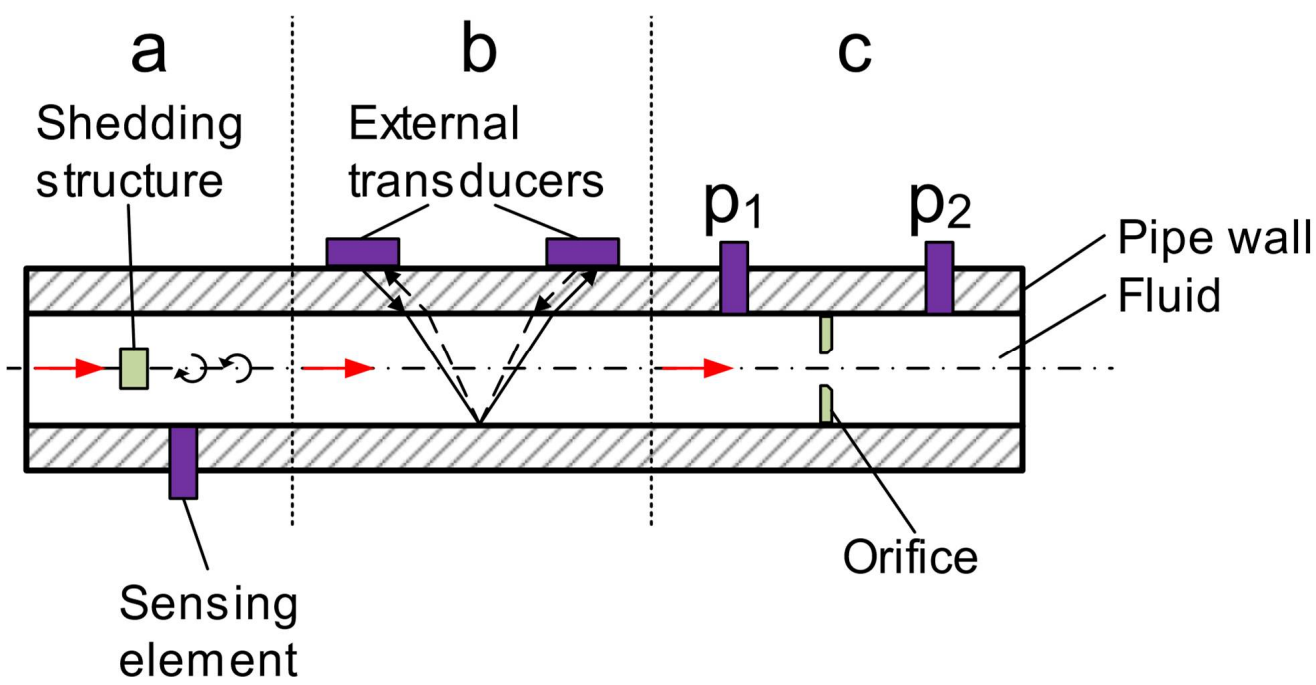

Figure 4. Volumetric flow meters, (a) vortex type with shedding structure and sensing element behind structure, (b) ultrasonic clamp-on flow meter with downstream ultrasonic path in filled line, upstream path with dashed line, (c) pressure drop flow meter with orifice plate.

The principle of vortex flow meters is based on the measurement of the frequency of triggered vortexes in the flow. The vortexes appear due to a special structure inserted into the flow path. Vortex flow meters are the usual choice for built-in instrumentation in plants with thermal oil as the HTF. They can also withstand the higher temperatures in plants with salt as the HTF, but long-term experiences in salt HTF circuits are still under investigation. Vortex flow meters have the advantage of causing low pressure drops and are suitable for large flow rates and pipe diameters [13]. Ultrasonic flow meters are based on the travel-time measurement of sound through the fluid. They do not need an installation inside the pipe and, therefore, can measure through the pipe wall. This makes them much more flexible and independent from the used HTF than in-pipe installations such as vortex flow meters. They are usually used for clamp-on devices with varying measurement locations in the field [12]. Clamp-on devices are rather used by experts. Data about the pipe material and wall thickness are needed and a correct and reproducible attachment of the device on the pipe surface is crucial. The pipe diameter to pipe wall thickness ratio $D / t$ should not be under 10 and the axial and angular placement of signal transducers should be according to the devices' specifications [14]. The coupling between the transducers and the pipe can be realized with coupling pads, gels or grease. The measurement principle of the pressure drop flow meters is based on an induced pressure drop, e.g., caused by an orifice. The measured pressure across the orifice provides information about the volumetric flow. Due to the significant pressure loss, this type of flow meter is rather used for low viscosity fluids and not in plants where thermal oil is used as the HTF. The only flow meter, which is directly measuring the mass flow, is the Coriolis type. The measurement principle is based on the Coriolis force, which acts on objects in a rotating reference system moving non-parallel to the rotational axis. In order to use this principle in a compact mass flow instrumentation, the rotational motion is replaced by vibrations on tubes inside the instrument. The measured phase-shift of the vibration correlates with the mass flow of the fluid inside, see Figure 5. 

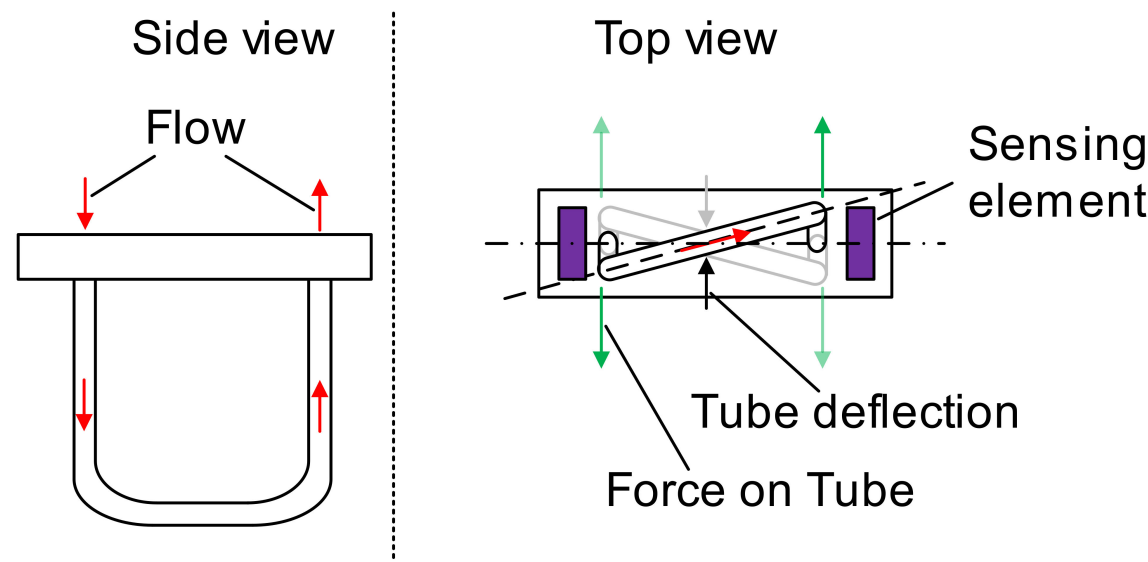

Figure 5. Coriolis mass flow meter in different phases of deflection, red arrows show flow direction, green arrows show the force on the tube due to the influence of coriolis acceleration, sensing elements measure twist of tube.

Coriolis flow meters are usually used in test facilities, because they provide the highest accuracy. The mass flow is determined directly and no additional temperature measurement and deviations in density data influence the measurement. The extensive use in the whole plant is limited due to the relatively small acceptable mass flow rate and the much higher initial costs for implementation in the field. Vortex flow meters represent the usual measurement configuration in parabolic trough fields with thermal oil and salt as the HTFs. Coriolis mass flow meters are usually used in test facility instrumentation. Orifice flow meters are applicable for low viscosity fluids to minimize the pressure drop. Ultrasonic clamp-on devices are used by experts for varying measurement locations in the field and can be used independently from the used HTF. The detailed measurement principles are not explained in detail in this paper. The interested reader is referred to comprehensive compilations [13]. A comparison of the accuracy of the different flow types shows that the Coriolis mass flow meter delivers the highest accuracy, followed by vortex and ultrasonic. The orifice pressure drop flow meter delivers the most inaccurate measurements. The uncertainty is assumed to be a $1 \sigma$ value, as nothing else is specified in the literature source. The costs for the flow meters are in the range of $\sim$ EUR 5000, with the exception of the Coriolis flow meter, which is in the range of $\sim$ EUR 10,000. Again, Table 1 only shows the instrument costs.

Table 1. Measurand, measuring device, measuring uncertainty and approximate cost range for standard HTF measurements in parabolic trough collector fields.

\begin{tabular}{|c|c|c|c|c|}
\hline Measurand & $\begin{array}{l}\text { Measuring Device and } \\
\text { Typical Application }\end{array}$ & Uncertainty Value & Definition & Cost Range \\
\hline \multirow{5}{*}{ Temperature } & $\begin{array}{c}\text { Pt-100 Type A } \\
\text { (for built-in sensor) }\end{array}$ & $\begin{array}{l} \pm 0.67 \mathrm{~K} @ 293^{\circ} \mathrm{C}\left(T_{\text {in }}\right) \\
\pm 0.76 \mathrm{~K} @ 393^{\circ} \mathrm{C}\left(T_{\text {out }}\right)\end{array}$ & $\begin{array}{c}u_{c}\left(T_{\text {in }}\right), u_{c}\left(T_{\text {out }}\right)^{a} \\
{[12]}\end{array}$ & EUR 100 \\
\hline & $\begin{array}{c}\text { Pt-100 Type A } \\
\text { (for clamp-on sensor) }\end{array}$ & $\pm 0.7 \mathrm{~K} @ 390^{\circ} \mathrm{C}$ & $\begin{array}{l}U\left(T_{\text {out }}\right) \text { with } k=2 \text {, correction } \\
\text { function and } R e>2 \times 10^{5}\end{array}$ & ＥUR 500 \\
\hline & $\begin{array}{l}\text { Pt-100 1/10 Type B } \\
\text { (for test facility) }\end{array}$ & $\begin{array}{l} \pm 0.13 \mathrm{~K} @ 293^{\circ} \mathrm{C}\left(T_{\text {in }}\right) \\
\pm 0.16 \mathrm{~K} @ 393^{\circ} \mathrm{C}\left(T_{\text {out }}\right)\end{array}$ & $\begin{array}{c}u_{c}\left(T_{\text {in }}\right), u_{c}\left(T_{\text {out }}\right)^{\mathrm{a}} \\
{[12]}\end{array}$ & EUR 100 \\
\hline & $\begin{array}{l}\text { Thermocouple Type } \mathrm{K} \text { (Class } 1 \text { ) } \\
\text { (general purpose from }-40^{\circ} \mathrm{C} \\
\text { to } 1000^{\circ} \mathrm{C} \text { ) }\end{array}$ & $\begin{array}{l} \pm 0.87 \mathrm{~K} @ 293{ }^{\circ} \mathrm{C}\left(T_{\text {in }}\right) \\
\pm 0.91 \mathrm{~K} @ 393^{\circ} \mathrm{C}\left(T_{\text {out }}\right)\end{array}$ & $\begin{array}{c}u\left(T_{\text {in }}\right), u\left(T_{\text {out }}\right)^{\mathrm{b}} \\
{[9]}\end{array}$ & ＥUR 100 \\
\hline & $\begin{array}{l}\text { Thermocouple Type } \mathrm{K} \text { (Class } 2 \text { ) } \\
\text { (general purpose from }-40^{\circ} \mathrm{C} \\
\text { to } 1200^{\circ} \mathrm{C} \text { ) }\end{array}$ & $\begin{array}{l} \pm 1.4 \mathrm{~K} @ 293{ }^{\circ} \mathrm{C}\left(T_{\text {in }}\right) \\
\pm 1.7 \mathrm{~K} @ 393^{\circ} \mathrm{C}\left(T_{\text {out }}\right)\end{array}$ & $\begin{array}{c}u\left(T_{\text {in }}\right), u\left(T_{\text {out }}\right)^{\mathrm{b}} \\
{[9]}\end{array}$ & EUR 100 \\
\hline
\end{tabular}


Table 1. Cont

\begin{tabular}{|c|c|c|c|c|}
\hline Measurand & $\begin{array}{l}\text { Measuring Device and } \\
\text { Typical Application }\end{array}$ & Uncertainty Value & Definition & Cost Range \\
\hline \multirow{3}{*}{ Volumetric flow meters } & $\begin{array}{c}\text { Vortex } \\
\text { (for built-in sensor) }\end{array}$ & \pm 0.038 kg/s @ 6.873 kg/s & $\begin{array}{c}u_{\mathrm{c}}\left(\dot{m}_{\mathrm{HTF}}\right)^{\mathrm{c}} \\
{[12]}\end{array}$ & ＥUR 5000 \\
\hline & $\begin{array}{c}\text { Ultrasonic } \\
\text { (for clamp-on) }\end{array}$ & \pm 0.055 kg/s @ 6.873 kg/s & $\begin{array}{c}u_{\mathrm{c}}\left(\dot{m}_{\mathrm{HTF}}\right)^{\mathrm{c}} \\
{[12]}\end{array}$ & ＥUR 5000 \\
\hline & $\begin{array}{c}\text { Pressure drop } \\
\text { (for low viscos fluids) }\end{array}$ & Typically $< \pm 2.0 \%$ & Assuming a $1 \sigma$ value [15] & EUR 5000 \\
\hline Mass flow meters & $\begin{array}{c}\text { Coriolis } \\
\text { (for test facility) }\end{array}$ & \pm 0.006 kg/s @ 6.873 kg/s & $\begin{array}{c}u_{\mathrm{c}}\left(\dot{m}_{\mathrm{HTF}}\right)^{\mathrm{c}} \\
{[12]}\end{array}$ & ＥUR 10,000 \\
\hline Pressure & $\begin{array}{l}\text { Piezoelectric, piezoresistive, } \\
\text { capacitance }\end{array}$ & $<0.1 \%$ of signal output & [13] & $\sim$ EUR 100 \\
\hline
\end{tabular}

${ }^{a}$ Combined standard uncertainty according to the GUM, including uncertainties from the sensor, repeatability, drift and transmitter. b Permissible deviation assumed as rectangular. Only sensor considered. ' Combined standard uncertainty according to the GUM, including uncertainties from temperature measurement. Density data uncertainties are included if volumetric flow is measured. Pipe diameter and analog to digital converter uncertainties are included if a clamp-on device is used.

\subsubsection{Pressure Transducers}

A further measurand for the control of the plant, the detection of overload and the specification of the HTF properties in the solar field, is the fluid pressure. It is an important measurand to determine pressure losses in the field and liquid level monitoring in the case of differential pressure measurement [16]. Moreover, the maximum pressure levels in different solar field parts and devices are monitored as well. In most of the industry applications, pressure measurements are carried out with electromechanical pressure transducers. They deliver highly accurate and easy to handle pressure indication in the form of an electrical signal. In safety applications, mechanical pressure gauges are often required as an additional safety feature, as they are not affected from outages and deliver a directly readable pressure value. To follow the scope of this paper and deliver a measurement overview for future developments in data analytics, only electromechanical pressure transducers are covered. These pressure sensors can again be divided into the following three sub-categories:

- Absolute pressure sensors;

- Gauge pressure sensors;

- Differential pressure sensors.

Absolute pressure sensors compare the measured pressure to a complete vacuum. Gauge sensors compare the measured pressure to atmospheric pressure. Differential pressure sensors measure the difference between two unknown pressures [5]. The usual way of measuring pressure is measuring the force acting on a known area [3]. Pressure transducers deliver electrical signals from the mechanical deflection of a diaphragm due to the influence of pressure. Common techniques use the change of resistance, capacitance or use the piezoelectric effect caused by a structural deformation induced by the pressure force. Calibration for midrange pressures can be carried out with U-tube manometers, dead-weight gauges and barometers as reference instruments [3]. Pressure transducers are industrial standard equipment and, therefore, rather cheap.

Temperature sensors, flow meters and pressure sensors represent standard measurement equipment, which is usually present in every plant engineering project. In the following paragraphs, the specific solar field instrumentation and findings in the context of the used instrumentation are shown.

\subsubsection{Special Measurement Equipment for Solar Collector Assembly (SCA) Tracking}

The next group of measurement devices is located at every single solar collector assembly (SCA). The SCA describes one collector unit, which is equally rotated and, in most cases, has one drive in the center of the SCA. For the exact positioning of the collector in the sun direction, two approaches, open and closed-loop tracking, are available [17]. In 
both cases, high accuracy is required for the positioning of the collector, the combination of the collector drive and the position sensor needs to be very precise. Table 2 includes information about the instrumentation for open- and closed-loop tracking.

Open-loop tracking uses highly accurate sun position algorithms such as the ones from Michalsky et al. [18] with an uncertainty of $\pm 0.01^{\circ}$ (from year 1950 to 2050) or the Solar Position Algorithm (SPA) [19] with an uncertainty of $\pm 0.0003^{\circ}$ (from year -2000 to 6000). These sun position algorithms determine the appropriate track angle of the SCA based on the location and the current date and time. The sun position for singleaxis tracking is the set point for the position control of the trough. The exact rotational position is determined by angle measurements from inclinometers attached at the collector structure or rotary encoders at the rotary joint of the SCA. The inclinometer measures the gravitational force on the device and, together with a previous calibration, determines the rotational position of the SCA. For SCA tracking, highly accurate inclinometers with measurement ranges $>180^{\circ}$ are needed. The rotary encoder assigns every angle position an individual signal for the drive control. The angle position determines whether the collector is in the right position relative to the position of the sun. Inclinometers can suffer from temperature-dependent deviations and devices that meet the before-mentioned requirements are comparably expensive. Magnetic band encoders are a type of rotary encoder suitable for harsh conditions and providing a high measurement resolution at the same time [3].

Closed-loop tracking systems use a feed backward element, which determines whether the trough is in track or not. These elements are often called "sun sensors". The sensor does not measure the absolute position of the SCA but the relative orientation of the collector, absorber tube and sun. The probable first implementation of a sun sensor for autonomous SCA drive control was patented in 1917 [20]. This implementation uses a thermopile or a thermostat as a sun sensor to drive the control mechanism for collector orientation. If the trough is not focused, the thermopile is exposed to the sun. An electric current from the thermopile moves a positioning motor until the trough is focused again and the thermopile is shadowed by the receiver tube. A more recent example for this system is a photovoltaic (PV) sun sensor with two PV cells that are positioned in the vertex of the parable shape [21]. In a focused state, the two PV cells are equally shadowed by the receiver tube and deliver the same voltage. Every divergent position delivers unequal voltage that serves as a feed backward signal for the drive system. To our knowledge, there is no publication available about the uncertainty of the achieved tracking angle. Parabolic troughs with sun sensors need additionally angle measurement devices. Since the sun sensors require partial shadowing from the receiver tube, they can only operate at angles closed to the actual tracking angle. If the collector is far out of focus, there is no direct irradiance on the sensor and the system cannot track. The angle measurement devices have lower accuracy requirements (uncertainty in the range of $\pm 0.1 \%$ ) compared to the open-loop system.

Relative measuring devices such as sun sensors are additional components with some disadvantages: They only measure the tracking offset at one location of the SCA, usually at the drive pylon. They increase the possibility of failures, are influenced by dust, absorber tube or sensor misalignments and other environmental conditions and possibly create higher costs. In general, the implementation of a closed-loop tracking system might be more appropriate in PV systems. These systems can use the whole global irradiance, whereas CSP systems can only use direct irradiance. Therefore, the optimized tracking angle for maximum system power might diverge from the actual sun position due to light scattering in overcast conditions. Both the absolute and relative measuring devices need to be designed for the harsh conditions of a solar field with a desert climate, preferably maintenance-free and durable to stay in the field for the whole lifetime of the plant. 


\subsubsection{Special Measurement Equipment for Solar Field Maintenance}

The temperature of the receiver glass tube or the outside of a pipe section provides information on the heat loss [22]. The glass temperature is generally low for well-insulated receivers having low heat losses, whereas it is high for defective receivers suffering from high heat losses. Environmental conditions such as temperature, wind speed, sky and ground temperature strongly influence the glass envelope temperature. A clear correlation between the glass envelope temperature and heat loss is possible, but not under all circumstances. For example, a receiver with an observed glass envelope temperature of $58{ }^{\circ} \mathrm{C}$ can be either a new receiver with low heat loss $\left(150 \mathrm{~W} / \mathrm{m}\right.$ at $350{ }^{\circ} \mathrm{C}$ HTF temperature) observed at near zero wind, or a defective receiver with high heat loss $(514 \mathrm{~W} / \mathrm{m})$ observed at an air speed of $6 \mathrm{~m} / \mathrm{s}$ [23]. These results show that the receiver glass temperature can only be used as an indicator for heat losses, if the air speed near the receiver tube is considered.

The temperature on extended surfaces can be measured using an infrared camera. The usual thermography equipment can be a hand-held device for manual measurements, or an airborne device, placed on an aerial vehicle (Section 3.2). The resulting measurements with hand-held devices represent only local samples of the field heat loss condition. Gathering the overall heat loss information of every heat collecting element (HCE) and all the piping is usually not possible with standard thermography equipment. The manufacturers of thermography devices usually publish the measuring accuracy of their devices. A general analysis of the uncertainty of thermography measurement is given in [24]. The typical measurement uncertainty is in the range of $\pm 1 \mathrm{~K}$, which is much higher than the uncertainties imposed by environmental conditions while interpreting the measured temperature.

The cleanliness of the reflectors is defined by the ratio of the direct specular reflectivity of soiled and clean mirror samples [12]. The cleanliness of the solar field directly affects the overall system performance of the CSP plant [25]. Cohen et al., show that a change in reflectivity of $1 \%$ results in a thermal performance change of about $1.2 \%$ [26]. The instruments presented here are devices suitable for field measurements, as this is the main use case in solar fields. Laboratory equipment is usually not available and not applicable for the operators. Field measurements are taken with portable reflectometers for single mirrors. The measurements are carried out at various spots on the mirror of interest. With this procedure, cleanliness spot measurements can be taken in the order of three to four measurements per minute [25]. Different reflectometers are used in solar fields [27]. They all have a similar optical working principle, based on the intensity measurement of the reflection from a light source with known wavelengths [28]. The beam from a light emitting diode (LED) with wavelengths in the solar spectrum is reflected by the mirror. The reflection is at incidence angles near normal. The acceptance angles should be comparable to those from the parabolic trough system. It is often required to have an average value of reflectivity across the solar field. Procedures to estimate the average value from a number of spot measurements are described in [29]. A model is used to calculate an average reflectance value for the solar field from the available spot measurements on pre-defined mirror panels. The objective of the method is to deliver measurements with an uncertainty below $1 \%$ under a $95 \%$ confidence level. However, due to the size of the solar field, the needed measurements for this procedure usually cannot be taken on one single day [30].

The geometrical accuracy of the collector strongly impacts the overall collector efficiency. The geometry of the reflector is influenced by the collector structure, the mirrors and the loads on the whole assembly. There are various methods for the assessment of the shape of the reflectors. In this section, two reliable methods are presented. On the one hand, the following deflectometric techniques: The Trough Absorber Reflection Measurement System (TARMES) [31-33], Video Scanning Hartmann Optical Test System (VSHOT) [34] and theoretical overlay photographic (TOP) [35]. These systems are going back to the distant observer method proposed by Wood in 1981 [36]. On the other hand, close-range photogrammetry $[37,38]$. All the systems use cameras to derive the shape of the mirrors. In TARMES, the SCA is changing its track angle, whereas the camera position stays in a fixed position. By evaluating the reflection of the absorber tube, it is possible to derive the 
mirror slope. The close-range photogrammetry generates a 3D-point cloud of the surface of the object using applied markers on the mirror surface. The 3D-point cloud can be post-processed to calculate a mirror slope. The deflectometric technique is usually chosen to generate highly resolved mirror slope deviation maps. The photogrammetric technique delivers maps with less resolution but can much more easily be applied for deformation studies of a collector structure, e.g., under different tracking elevation angles.

Table 2. Measurand, measuring device, measuring uncertainty and approximate cost range for specific measurements for parabolic trough collector fields.

\begin{tabular}{|c|c|c|c|c|}
\hline Measurand & Measuring Device & $\begin{array}{l}\text { Typical Uncertainty/ } \\
\text { Accuracy/Precision }\end{array}$ & Definition & Cost Range \\
\hline $\begin{array}{l}\text { Receiver glass/piping } \\
\text { temperature }\end{array}$ & Thermography & $\pm 1 \mathrm{~K}$ or $\pm 1 \%$ & $\begin{array}{c}\text { Measurement accuracy } \\
\text { from }[39,40]\end{array}$ & $\sim$ EUR 5000 \\
\hline \multirow{3}{*}{ SCA angle } & Inclinometer & $\pm 0.07^{\circ}$ to $\pm 0.5^{\circ}$ & $\begin{array}{c}\text { Upper cost range for } \\
\text { highly accurate devices } \\
\text { with measuring } \\
\text { range }>180^{\circ}\end{array}$ & $\sim$ EUR 100 to $\sim$ EUR 1000 \\
\hline & Rotary encoder & $\pm 0.01^{\circ}$ to $\pm 0.1^{\circ}$ & Magnetic band encoder & $\sim$ EUR 100 \\
\hline & Sun sensor & - & $\begin{array}{l}\text { Closed-loop } \\
\text { tracking system }\end{array}$ & EUR 100 to EUR 300 \\
\hline Cleanliness & Reflectometer & $\pm 0.6 \%$ & $\begin{array}{c}u_{\mathrm{c}}(\chi)^{\mathrm{a}} \\
{[12]}\end{array}$ & $\sim$ EUR 1000 \\
\hline \multirow{2}{*}{ Mirror shape } & $\begin{array}{l}\text { Deflectometry } \\
\text { (e.g., TARMES) }\end{array}$ & \pm 0.6 to $\pm 1.0 \mathrm{mrad}$ & $\begin{array}{l}\text { According to the GUM } \\
\text { standard [31] }\end{array}$ & $\sim$ EUR 10,000 \\
\hline & Photogrammetry & $1: 50,000$ or better & $\begin{array}{c}\text { Precision of coordinate } \\
\text { measurements [38] }\end{array}$ & $\sim$ EUR 10,000 \\
\hline
\end{tabular}

${ }^{\text {a }}$ Combined standard uncertainty according to the GUM, including uncertainties from signal and soiling.

2.1.7. Meteorological Instrumentation

Irradiance Data

The last group of the presented solar field instrumentation is the meteorological measurement equipment. The measurement of the solar radiation is separately discussed in the two following paragraphs due to its importance for the determination of the available energy in the CSP plant. A summary is given in Table 3. The direct normal irradiance (DNI) is the useable part of the solar irradiance for CSP applications. The methods for the DNI measurement are direct measurements with pyrheliometers and indirect measurements with pyranometer or rotating shadow band irradiometers (RSI).

Pyrheliometers consist basically of a sensor element, which is placed at a defined distance behind an aperture. As a result of this geometrical setup, the sensor only recognizes irradiance at small acceptance angles of $\pm 2.5^{\circ}$ deviation from the optical axis. With the optical axis continuously tracked towards the sun, the sensor measures the DNI. As long as the instrument is appropriately maintained, the pyrheliometer has the highest accuracy.

Pyranometers for field applications mainly consist of a blacked thermopile as the sensor element, which is placed under one or two glass domes [16]. A pyranometer measures the global irradiance. Two pyranometers are necessary for an indirect measurement of the DNI. One to measure the global horizontal irradiance (GHI) and one with a shading structure to measure the diffuse horizontal irradiance (DHI). The relation between the GHI, the DHI and the DNI is given by Equation (2), where $\theta_{z}$ is the zenith angle [41], as follows:

$$
\mathrm{GHI}=\mathrm{DHI}+\mathrm{DNI} \times \cos \left(\theta_{\mathrm{z}}\right)
$$


The measurements of the DHI are usually carried out with a diffusometer, which is a pyranometer and a shading structure to shield it from direct radiation. The shielding is usually carried out by a ring, disc or ball. Shading discs or balls deliver more accurate measurements than shading rings. In any case, a correction function is needed to account for the irradiance deviations due to the shading structure.

A rotating shadow band irradiometer (RSI) usually consists of a silicon-based pyranometer and a shading structure rotated around the pyranometer. The shading device is often called a shadow band. The system measures alternating values of GHI and DHI. From those values, the DNI is derived. The GHI values result from the measurement with the shadow band in a resting position, whereas the DHI values result from the measurement with the shadow band in a shielding position. As for the diffusometer a correction function is needed to account for the irradiance deviations due to the shading structure.

The above devices only reach their theoretical accuracy if they are well maintained. This includes a recent calibration and a clean sensor cover. For soiled sensors, the resulting DNI values may deviate by up to $25 \%$ after only a few weeks [42]. Pyrheliometers generally show the highest impact of soiling on the measured DNI values, whereas the soiling influence on RSI measurements is lower $[43,44]$.

The instruments generally measure a contribution of circumsolar radiation. This part of radiation emanates from the circumsolar region and can be described as a function of the angular position, relative to the center of the sun [45]. The circumsolar radiation exists due to forward light scattering in the atmosphere. As the acceptance angle of the DNI measurement device might differ from the acceptance angle of a concentrating collector, it is important to understand the quantity of circumsolar radiation. Sunshape, circumsolar ratio or circumsolar contribution can be measured with several approaches.

The scientific instruments are a circumsolar telescope from the Lawrence Berkeley Laboratory (LBL) [46], a DLR sunshape camera [47] and a Sun and Aureole Measurement system (SAM) combined with a Cimel sun photometer [48]. The circumsolar telescope from LBL and the DLR sunshape camera are outdated and not available anymore. The more recent developments are the high resolution circumsolar measurement system [49]. Most of these systems are scientific approaches to measure the circumsolar radiation with high accuracies. The measurement with two pyrheliometers with different acceptance angles [48] and the measurement with an RSI [50] are more relevant for industrial applications. The latter is beneficial, as it is a low-cost alternative with reasonable measurement accuracies. Moreover, the RSI can be used, on the one hand, for the measurement of standard radiation data, such as the GHI, the DHI and the DNI and, on the other hand, for the determination of the sunshape. A software extension for the RSI analyses the burst, while the shadow structure passes by the sensor.

Table 3. Measurand, measuring device, measuring uncertainty and approximate cost range for irradiance data measurement equipment in parabolic trough collector fields.

\begin{tabular}{|c|c|c|c|c|}
\hline Measurand & Measuring Device & Uncertainty Value & Definition & Cost Range \\
\hline \multirow{2}{*}{ DNI } & $\begin{array}{l}\text { Pyrheliometer with } \\
\text { tracking equipment }\end{array}$ & $\pm 1.1 \%$ & $\begin{array}{c}u_{\mathrm{c}}(D N I)^{\mathrm{a}} \\
{[12]}\end{array}$ & >EUR 25,000 \\
\hline & $\begin{array}{l}\text { Rotating Shadowband } \\
\text { Irradiometer }\end{array}$ & $\pm 2.9 \%$ & $\begin{array}{c}u_{\mathrm{c}}(D N I)^{\mathrm{b}} \\
{[51]}\end{array}$ & EUR 9000 \\
\hline \multirow{2}{*}{ GHI } & Pyranometer & $\pm 2 \%$ & $\begin{array}{c}u_{\mathrm{c}}(G H I) \\
{[16]}\end{array}$ & EUR 5000 \\
\hline & $\begin{array}{l}\text { Rotating Shadowband } \\
\text { Irradiometer }\end{array}$ & $\pm 2.0 \%$ & $\begin{array}{c}u_{\mathrm{c}}(G H I)^{\mathrm{b}} \\
{[16]}\end{array}$ & EUR 9000 \\
\hline
\end{tabular}


Table 3. Cont.

\begin{tabular}{|c|c|c|c|c|}
\hline Measurand & Measuring Device & Uncertainty Value & Definition & Cost Range \\
\hline \multirow[b]{2}{*}{ DHI } & $\begin{array}{l}\text { Rotating Shadowband } \\
\text { Irradiometer }\end{array}$ & $\pm 3.3 \%$ & $\begin{array}{c}u_{\mathrm{c}}(D H I)^{\mathrm{b}} \\
{[51]}\end{array}$ & EUR 9000 \\
\hline & $\begin{array}{l}\text { Diffusometer (Pyranometer } \\
\text { and shading structure) }\end{array}$ & $> \pm 2 \%$ & $\begin{array}{c}u_{\mathrm{c}}(D H I)[16], \text { shading } \\
\text { structure increases } \\
\text { uncertainty }\end{array}$ & $\sim$ EUR 5000 \\
\hline \multirow[t]{2}{*}{ Circumsolar radiation } & $\begin{array}{l}\text { Rotating Shadowband } \\
\text { Irradiometer }\end{array}$ & - & $\begin{array}{l}\text { In [45] compared to SAM } \\
\text { combined with Cimel sun } \\
\text { photometer and dedicated } \\
\text { software. }\end{array}$ & EUR 9000 \\
\hline & $\begin{array}{l}\text { Two Pyrheliometers with } \\
\text { different acceptance angles }\end{array}$ & - & $\begin{array}{l}\text { System described in [52], in } \\
\text { [48] compared to SAM }\end{array}$ & $>$ EUR 25,000 \\
\hline
\end{tabular}

\footnotetext{
${ }^{\text {a C}}$ Combined standard uncertainty according to the GUM, including uncertainties from sensor, calibration and transmitter and DNI $=750 \mathrm{~W} / \mathrm{m}^{2}$.

${ }^{b}$ Combined standard uncertainty according to the GUM, including uncertainties from calibration, zenith- and azimuth-response, nonlinearity, temperature-response, aging, maintenance, leveling, shading, spectral error and logger. 10 min data, with correction function, for DNI measurement GHI and DNI over $300 \mathrm{~W} / \mathrm{m}^{2}$.
}

\section{Standard Meteorological Instrumentation}

This section describes the standard equipment of meteorological ground stations normally found in CSP installations, see Table 4. These stations are typically realized as automatic stations with electronic measuring instrumentation. Every solar field is usually equipped with at least one meteorological measurement station. The station is preferably installed well before the plant is erected to deliver reliable values over a long period at the site. Standard meteorological values such as the dry bulb temperature, atmospheric pressure, relative humidity, wind (gust) speed and precipitation are usually recorded. These values are needed to compare the performance of the solar field and power block with the expected performance and can help to make weather predictions more accurate and site specific. The weather directly influences the power of the solar thermal power plant, e.g., the dry bulb temperature directly influences all the heat losses in the system [53] as well as the back cooling capacity of the power block. If the power block is equipped with a wet cooling system, its capacity is further influenced by the relative humidity.

The measurement of the dry bulb air temperature can be carried out with resistance thermometers, semiconductor thermometers or thermocouples. The standards for the thermometer exposure and siting should be applied, i.e., radiation shielding, free circulation of air and a height between 1.25 and $2 \mathrm{~m}$ above ground level [54].

Pressure measurements must be carried out in an environment connected to the atmospheric pressure that is not affected by external influences such as wind, radiation, temperature, mechanical influences such as shocks and vibrations, or fluctuation in electrical power supply [54]. Common atmospheric pressure measurements are carried out with aneroid displacement transducers, digital piezo resistive and cylindrical resonator barometers [54].

Relative humidity measurements with electric sensor elements are mainly used for CSP applications due to their remote-reading ability. The sensor technologies are based on electrical resistance and capacitance measurements. The standards for exposure and siting are primarily the prevention from liquid water entering the sensor element and the mounting inside a thermometer screen [54].

The measurement of wind velocity in the solar field is relevant for the comparison with detailed heat loss models $[53,55]$. The measurement of the wind gust speed is particularly relevant for the maximum allowable load on the collectors and, therefore, for the safe operation of the solar field. The measurement of peak gusts requires a measurement frequency of at least $4 \mathrm{~Hz}$. Lower sampling rates can underestimate the occurring maximum wind speed [54]. Typical values for tolerated maximum wind speed are $14 \mathrm{~m} / \mathrm{s}$. Drives of the collectors are able to move them to a stow position at wind speeds of up to $20 \mathrm{~m} / \mathrm{s}$. 
Wind measurements are usually carried out with cup, propeller or ultrasonic anemometers. Cup and propeller anemometers derive the wind velocity in one direction from the rotation frequency of the rotor. Due to their mechanical measurement principle, they have a threshold of $4 \mathrm{~m} / \mathrm{s}$ [54]. Propeller anemometers can be combined with wind vanes to determine the horizontal wind direction. Cup anemometers need a separate wind vane for the measurement of the horizontal wind direction. The measurement principle of ultrasonic anemometers is based on the measurement of the traveling time of an ultrasonic pulse. They deliver a higher measurement frequency, are available in designs to measure wind velocities in three dimensions and are robust in a harsh environment. Ultrasonic anemometers are usually more expensive than cup anemometers. Since wind speed increases with the height above the ground, the standard measurement height is $10 \mathrm{~m}$ above open terrain. The term open terrain is defined as "An area where the distance between the anemometer and any obstruction is at least 10 times the height of the obstruction" [54]. As these spots are rare in CSP plants, the measured values can only approximate the ideal value.

Precipitation gauges are sometimes installed in meteorological ground stations at CSP sites. They give information about rainfall events and give an idea of the local water availability. With regard to soiling rate models [56], knowledge about rainfall is important as an model input and the installation of precipitation gauges should be mandatory. The devices usually measure the weight or volume of the precipitation separated in single catches. The measurement is in particular sensitive to wind. A windbreak can, therefore, reduce this influence. The station should be mounted 0.5 to $1.5 \mathrm{~m}$ above the ground [54].

The aforementioned is focused on CSP applications. More details on general meteorological measurement instrumentation can be found in [54].

Table 4. Measurand, measuring device, measuring uncertainty and approximate cost range for additional meteorological measurement equipment in parabolic trough collector fields.

\begin{tabular}{|c|c|c|c|c|}
\hline Measurand & Measuring Device & Uncertainty Value & Definition & Cost Range \\
\hline \multirow{2}{*}{$\begin{array}{l}\text { Ambient air } \\
\text { temperature }\end{array}$} & $\begin{array}{l}\text { Pt-100 Type A with } \\
\text { radiation shielding }\end{array}$ & \multirow[t]{2}{*}{$\begin{array}{l} \pm 0.1 \mathrm{~K}(2 \sigma) \text { for }>-40^{\circ} \mathrm{C} \\
\text { and } \leq+40{ }^{\circ} \mathrm{C}\end{array}$} & \multirow[t]{2}{*}{$\begin{array}{l}\text { Required measurement } \\
\text { uncertainty [54] }\end{array}$} & $\sim$ EUR 100 \\
\hline & $\begin{array}{l}\text { Semiconductor thermometers with } \\
\text { radiation shielding }\end{array}$ & & & $\sim$ EUR 100 \\
\hline \multirow{2}{*}{ Relative humidity } & Capacitive hygrometer & \multirow{2}{*}{ $\pm 1 \%(2 \sigma)$} & \multirow{2}{*}{$\begin{array}{l}\text { Required measurement } \\
\text { uncertainty [54] }\end{array}$} & $\sim$ EUR 100 \\
\hline & Resistance hygrometer & & & ＥUR 100 \\
\hline \multirow{3}{*}{ Barometric pressure } & Aneroid displacement transducers & \multirow{3}{*}{$0.1 \mathrm{hPa}(2 \sigma)$} & \multirow{3}{*}{$\begin{array}{l}\text { Required measurement } \\
\text { uncertainty [54] }\end{array}$} & \multirow{3}{*}{$\sim$ EUR 100} \\
\hline & Digital piezo resistive barometers & & & \\
\hline & Cylindrical resonator barometers & & & \\
\hline \multirow{2}{*}{ Wind speed } & Cup anemometer & \multirow{2}{*}{$\begin{array}{c}0.5 \mathrm{~m} / \mathrm{s}(2 \sigma) \text { for } \leq 5 \mathrm{~m} / \mathrm{s} \\
10 \% \text { for }>5 \mathrm{~m} / \mathrm{s}\end{array}$} & \multirow{2}{*}{$\begin{array}{c}\text { Required measurement } \\
\text { uncertainty (Average over } \\
2 \text { and/or } 10 \mathrm{~min} . \text {.) [54] }\end{array}$} & $\sim$ EUR 1000 \\
\hline & Ultrasonic anemometer & & & $\sim$ EUR 5000 \\
\hline Wind gust & Ultrasonic anemometer & $10 \%(2 \sigma)$ & $\begin{array}{l}\text { Required measurement } \\
\text { uncertainty [54] }\end{array}$ & $\sim$ EUR 5000 \\
\hline Wind direction & Wind vane & $5^{\circ}(2 \sigma)$ & $\begin{array}{l}\text { Required measurement } \\
\text { uncertainty }{ }^{a}[54]\end{array}$ & $\sim$ EUR 1000 \\
\hline Daily precipitation & Precipitation gauge & $\begin{array}{c}0.1 \mathrm{~mm}(2 \sigma) \text { for } \leq 5 \mathrm{~mm} \\
2 \% \text { for }>5 \mathrm{~mm}\end{array}$ & $\begin{array}{l}\text { Required measurement } \\
\text { uncertainty [54] }\end{array}$ & $\sim$ EUR 1000 \\
\hline
\end{tabular}

a Average over 2 and/or $10 \mathrm{~min}$.

\subsection{Location of Stationary Measurement Devices in the Solar Field}

The number and location of the stationary instrumentation is mainly a decision of requirements and costs. Figure 6 shows the possible locations of measurement equipment for a typical solar field layout with four subfields and four SCAs per loop. For a better overview, only one subfield with one regular and one optional fully instrumented loop is shown. 
A full instrumented loop is equipped with the additional measurement instrumentation required for measurements on a loop level. This is flow measurement at a loop inlet, pressure measurement at a loop inlet and outlet and temperature measurement at a loop inlet. Apart from this additional equipment, the full instrumented loops are equal to regular loops. The position of the full instrumented loop can vary between the different subfields. The reason for this is to give meaningful measurement data independent from the loop position.

The different measuring devices in Figure 6 are depicted with different symbols. The measurands are temperature, tilt angle and an optional sun sensor. They are used locally to control the SCA drives, in order to achieve a high focus rate of the collector, without overheating the HTF. The measurements are usually transmitted to the central control station. Within a loop, the measurements are usually taken at each SCA drive pylon, in the center of the SCA. This layout has the advantage of minimal wiring effort, but disadvantages in SCA control. The feed-back controller uses the temperature measurement in the middle of the SCA, although the temperature at the end of the SCA would be the critical one regarding HTF overheating. Usually, an additional temperature sensor is installed at the outlet of the last SCA in the loop. This value is used as a trigger for defocusing the loop in case critical temperature limits are exceeded. Temperature readings can be checked for errors to detect failures in the measurement system and avoid malfunction of the control system.

\section{Subfield 1}

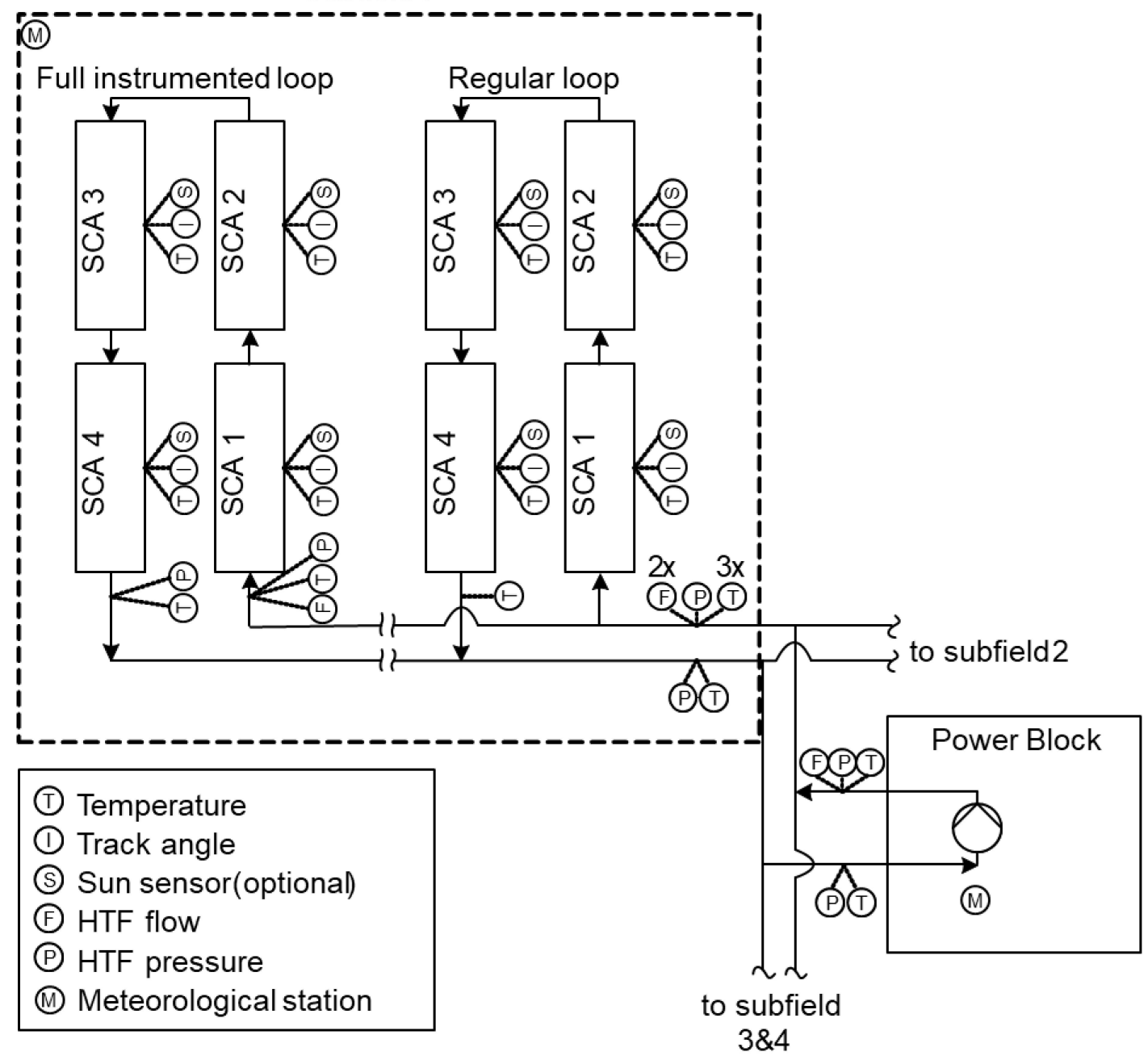

Figure 6. Spatial distribution of stationary measurement devices in the solar field. 
Apart from the loop instrumentation, several sensors are installed in the rest of the piping system. The subfield inlet and outlet HTF temperatures and the HTF flow at the subfield inlet are typically measured. The HTF pressure at the subfield inlet and outlet are optional measurements present in some solar fields. The flow and temperature measurements are particularly important for the determination of the thermal power generated in the subfield. Therefore, these measurands can be collected from more than one sensor, e.g., temperature with three sensors, flow with two sensors. With this redundancy, the system is resilient against failures of single sensors. The entire solar field yield operation is recorded via a redundant flow meter and temperature sensor at the power block interface. Additional pressure sensors are installed to monitor the HTF pump in the power block. The sensors at the power block may also be in a redundant manner, to deliver reliable information about the usable heat for the power block heat exchanger. Solar fields with individual loop control valves have additional position encoders for the valves and may have differential pressure measurement over the valves. At least one meteorological station is usually installed in the center of the plant or outside of the solar field. In case of multiple stations, they are distributed over the solar field to deliver an averaged value of, e.g., the DNI. The installation of the meteorological station in the corners of the solar field helps to identify changes, e.g., in cloud coverage, early.

Data for the control system are provided with small time intervals of $<1 \mathrm{~s}$. The recording of the data uses longer intervals of 2 to $10 \mathrm{~s}$. The database size for one day of operational and meteorological data results to $\sim 1 \mathrm{~GB}$.

\subsection{HTF Sample Laboratory Analysis}

During operation, the HTF may undergo changes in the chemical composition and thus in its physical characteristics. Currently, in most of the parabolic trough plants, a eutectic mixture of Biphenyl and Diphenyl oxide is used. Due to the high operating temperature $\left(\sim 393^{\circ} \mathrm{C}\right)$, close to the thermal stability limit of the fluid $\left(\sim 400^{\circ} \mathrm{C}\right)$, degradation products with low and high boiling points are formed [57]. Most importantly, in this context, are the formation of hydrogen and changes in the specific heat capacity. Precise knowledge of the heat capacity is required to calculate the actual thermal power via the mass flow, temperature rise and heat capacity. In order to monitor the degradation of the HTF hydrogen content [58] and specific heat capacity [59], fluid samples are analyzed on a regular basis. These analyses require methods for sample collection and laboratory equipment to quantify the HTF properties. In order to reduce hydrogen formation and further increase the operation temperature of the parabolic trough plant, alternative siliconebased HTFs are currently under development [60].

To extract representative HTF samples, hydrogen tight steel cylinders with high temperature valves are directly connected to the HTF cycle. The filling can be carried out, for example, with a flow through method with two cylinders, with one evacuated cylinder or by using a bypass between the loop inlet and outlet [58].

At ambient conditions in the laboratory, the HTF samples contain a gaseous and a liquid phase. The gaseous phase typically contains more than $90 \%$ of the hydrogen. The hydrogen content of the gaseous phase is calculated from the pressure above the liquid, the gas composition, the volume of the cylinder, the mass of the HTF and the density of the HTF. The general gas constant and the absolute sample temperature is also required. The hydrogen content in the liquid is calculated with the partial pressure of hydrogen, the mass, the Henry coefficient and the molar mass of the HTF. The total amount of hydrogen can be calculated as a molar concentration by adding the gaseous and liquid contents related to the HTF mass [58].

The heat capacity of the HTF can be measured with Differential Scanning Calorimetry (DSC) [59], see Table 5. This technique uses the difference of the amount of heat required to increase the temperature of the sample and a reference. 
Table 5. Measurand, measuring device, measuring uncertainty and approximate cost range for HTF Sample Laboratory Analysis.

\begin{tabular}{|c|c|c|c|c|}
\hline Measurand & $\begin{array}{l}\text { Measuring } \\
\text { Device }\end{array}$ & $\begin{array}{l}\text { Uncertainty } \\
\text { Value }\end{array}$ & Definition & Cost Range \\
\hline $\begin{array}{c}\text { Specific heat } \\
\text { capacity }\end{array}$ & $\begin{array}{l}\text { Differential } \\
\text { Scanning } \\
\text { Calorimetry } \\
\text { (DSC) }\end{array}$ & $\begin{array}{c} \pm 0.074 \mathrm{~J} / \mathrm{g} \mathrm{K} \\
(3.09 \%)(2 \sigma)\end{array}$ & $\begin{array}{c}\text { Measured for } \\
\text { Therminol VP-1 } \\
\text { between } 300 \text { and } \\
370{ }^{\circ} \mathrm{C}[61]\end{array}$ & $>$ EUR 10,000 \\
\hline
\end{tabular}

\section{New Approaches in Collector Field Monitoring}

While the last sections describe "standard" solar field instrumentation, this section is dedicated to advanced approaches. An overview about recent research is given in [62]. Some of these monitoring approaches are leaving the sector of research and are gaining influence in industrial practice. They are the basis for further optimization developments to decrease the levelized cost of energy (LCOE) and increase the reliability and dispatchability of the plants. By increasing the amount of information on the solar field, such approaches offer input to data-driven approaches such as autonomous collector optimization, predictive maintenance and optimized control strategies. In this paper, the following measurement techniques are chosen, because they do the following:

- deliver more information about the field specific conditions,

- measure in shorter time periods,

- deliver spatially higher resolved information,

- deliver measurements that can be used for advanced field control strategies.

Table 6 gives a short comparison of the standard measurement techniques and advanced approaches together with their potential improvements.

Table 6. Direct comparison of standard measurement techniques and new approaches in collector field monitoring.

\begin{tabular}{|c|c|c|}
\hline Standard Measurement Technique & New Approaches & Improvement \\
\hline \multirow[t]{2}{*}{ Hand-held infrared camera } & Vehicle-mounted instrumentation & $\begin{array}{l}\text { Spatially higher resolved, measures in } \\
\text { shorter time periods }\end{array}$ \\
\hline & Airborne measurements & Spatially higher resolved \\
\hline $\begin{array}{l}\text { Distant observer methods, } \\
\text { close-range photogrammetry }\end{array}$ & Airborne measurements & Spatially higher resolved \\
\hline Reflectometer measurements & Tracking cleanliness sensor & $\begin{array}{l}\text { Delivers more information, measures in } \\
\text { shorter time periods }\end{array}$ \\
\hline DNI measurements & All sky imagers, shadow cameras & $\begin{array}{l}\text { Spatially higher resolved, information } \\
\text { can be used for advanced field control }\end{array}$ \\
\hline Differential Scanning Calorimetry & In situ calorimeter & Delivers more information \\
\hline
\end{tabular}

The methods are explained in the following and summarized in Table 7 according to their measurand, the name of the device, their measurement uncertainty and a literature reference.

\subsection{Vehicle-Mounted Instrumentation}

As stated in Section 2.1.6, the measurement of excessive heat losses by determining the surface temperature of pipes and tubes with hand-held devices is very time consuming. Moreover, this procedure is not able to deliver spatially distributed information about surface temperatures. A more advanced approach for the inspection of larger fractions of the field is the Inspection Receiver Tubes (ITR) system introduced in [63] and further applied in [64]. This method consists of a thermography device placed on a vehicle. The software automatically detects each HCE and measures the glass surface temperature. Based on this temperature, an outlier analysis classifies the HCEs status in three different 
groups [64]. With this system, one single operator can measure around 4000 [64] to 7000 [63] HCEs per day. The measurement uncertainty is bigger than with just a hand-held device, see Table 7; but regarding the quantity of possible measurements, this could be tolerable.

\subsection{Airborne Measurements}

Even higher flexibility than vehicle-mounted instrumentation can be reached using airborne measurement systems. These systems give the possibility to perform measurement campaigns on large areas of the solar field much faster than with ground-based vehicles and, therefore, deliver data of the field condition with high spatial resolution. Hand-held measurement systems can only deliver sample measurements and local events may be overlooked. Although a lot of research groups looked at the development and possible future application of unmanned aerial vehicle (UAV) technology, Jorgensen et al. [65] first documented the potential of airborne implementation of the distant observer method [36] and infrared (IR) camera based receiver tube characterization to large parabolic trough collector fields. One representative of such a measurement system is the so-called QFly system. This system is basically an unmanned aerial vehicle (UAV), with flexible measurement instrumentation and software for image analysis. The first version of the airborne measurement system was equipped with a camera to measure the collector shape [33]. The external camera orientation for the photos is measured using photogrammetry. Afterwards, the mirror slope errors can be derived using the reflection of the absorber tubes in the mirror, similar to TARMES [32], Section 2.1.6. Compared to the TARMES system, where the collector needs to be moved into a specific position, the airborne deflectometry concept is independent of the collector position due to the moving camera. For slope error measurements, the collector is slightly defocused to reduce disturbing reflections. Measurements of tracking errors can be carried out with focused collectors. Apart from higher flexibility, measurements can be carried out with the actual operational loads on the collector. Pottler et al. [38] showed that the mirror shape changes with different collector positions due to gravitational force.

In addition to the mirror slope errors of a collector, airborne photogrammetry systems can be used to determine any absorber tube displacement. The camera position is measured with photogrammetry using mirror features, such as gaps, corners and crosses. The receiver tube displacement is calculated from the pairwise intersection of the measured tube center lines compared to the ideal focal line. This method allows image acquisition for a EuroTrough SCA in one hour. Post processing requires another three hours, depending on the computational performance [66].

Airborne infrared camera systems allow for the measurement of the surface temperature of the receiver glass covers or the outside of the pipe insulation. The thermography measurement can be applied to detect unusually high heat losses. In comparison to handheld devices, the airborne approach is able to cover much larger areas of the field in detail. During one working shift, data from around $25 \%$ of the whole field can be captured [67]. The measurement uncertainty is comparable to the vehicle-mounted system, see Table 7.

Airborne measurement systems are prone to wind influence. Prahl et al. [67] limited the usage of their system to wind speeds below 6 to $8 \mathrm{~m} / \mathrm{s}$. Gusts could also worsen the image quality. Nevertheless, with the flexibility of the airborne system, more applications are possible, as the payload of the UAV may be any type of sensor, which delivers usable information about the solar field condition. Possible applications are the determination of mirror cleanliness with a camera in the visible range and software for image evaluation [68], and maybe in the future, even the detection of leakages with a gas sensor mounted on the UAV [69].

\subsection{On-Site Measurements}

The measurement systems presented in this section are located in the solar field and can be divided into a spot measurement system, a system to deliver spatially resolved data and an in situ measurement system. 
The spot measurements deliver highly accurate information about specified measurands, with the aim to improve the existing measurements. In addition to the state-of-the art systems, one recent advantage in on-site measurement technology are systems to continuously measure the cleanliness value of a mirror sample, e.g., the Automated In situ Measurement of Contamination Quotas and Spectrums (AVUS) [70,71] and the Tracking Cleanliness Sensor (TraCS) [28]. With both systems, the soiling rates can be continuously determined at a single point in the solar field. In the AVUS system, mirror examples are exposed to the environment at a certain orientation and inclination. In regular intervals, the mirrors are automatically moved to an optical port, where reflectance is measured. The exposed mirror samples are used until a defined soiling level is reached. Afterwards, the samples are exchanged and stored for further analysis. Together with a linear transfer method, the system shows good accordance with the D\&S reflectometer. The latest version of TraCS ( $\mathrm{v} 2.0$ ) includes the following three basic components: two pyrheliometers and a rotating test mirror. One pyrheliometer measures the DNI directly, and the other one determines the DNI via the reflections of the mirror sample. For the DNI measurement, the whole system tracks the sun. The measurement uncertainty of the system is given in Table 7. From the soiling of the mirror sample the average soiling rates for mirrors or instruments can be derived. One application is the correction for the DNI measurements with pyrheliometers, which are highly influenced by soiling effects. The system should be installed close to the area of interest, as the soiling rates can be highly dependent on the location in the field [26]. Having such measurements available over larger periods of time, a soiling data basis can be derived. This can be used in the validation of soiling models [56] for short-time yield predictions, or even in advance for a CSP site assessment.

A further group representing the recent development of on-site measurement systems deliver spatially resolved DNI data in the form of DNI maps for the whole CSP plant. This can be achieved with the use of one or multiple all sky imagers (ASI) [72] or with a shadow camera system [73]. ASI systems deliver DNI data for the whole plant with a resolution of $20 \times 20 \mathrm{~m}^{2}$, the shadow camera system delivers a resolution of $5 \times 5 \mathrm{~m}^{2}$. Both systems track the cloud movements and, therefore, deliver short-term forecasts of up to $30 \mathrm{~min}$. These forecasts can be used for advanced control strategies in the solar field and make it possible to increase the total yield of the plant by up to $2 \%[74,75]$. Another option is the usage in high resolution solar field models for detailed simulations of the behavior of the field in transient situations [76,77]. The uncertainty of the measurements and forecasts are high compared to the standard DNI measurements, see Table 7 . Considering that the system delivers spatially distributed DNI forecasts in unstable cloudy conditions, the uncertainties are acceptable.

The last group of the presented advanced measurement approaches are the in situ measurements. The scope of the system presented in this section is the determination of the specific heat capacity of the HTF. This is an important value for the determination of the overall plant performance [78]. The calorimeter developed by Marchã et al. [79] is an improvement of the system from Collares-Pereira et al. [80]. The specific heat capacity measurement consists of an insulated cylindrical calorimeter with inner and outer chambers, inlet and outlet Pt-100 temperature measurements, and a Coriolis flow meter. With this simple setup, measurements up to $180^{\circ} \mathrm{C}$ were possible. An upper limit for the accuracy is given in Table 7. A more complex system is the concentrator test facility in Almería, Spain (KONTAS CP) [81]. The flow through calorimeter consists of a Coriolis mass flow meter, redundant Pt-100 temperature measurements, an electric heater and static mixers located in front of the temperature measurements. The mass flow is split into a measurement section and protection section to ensure a zero-heat flux boundary at the borders of the energy balance volume and to ensure steady state conditions for the measurements. It is designed for collector test facilities to reduce the influence of the uncertainties of the specific heat capacity on the performance assessment. Another possibility is to install this system in a regular plant and to determine the specific 
heat of the HTF continuously. Therefore, changes in the specific heat capacity can be recorded in order to monitor the HTF properties over the fluid lifetime, alternatively to a continuous sampling and laboratory analyses. The relative uncertainty of this system is given in Table 7 .

Table 7. Selected new measurement approaches for the monitoring of parabolic trough fields.

\begin{tabular}{|c|c|c|c|}
\hline Measurand & Measuring Device & Uncertainty Value & Definition \\
\hline Mirror shape & $\begin{array}{l}\text { Airborne deflectometry, values } \\
\text { from [33] }\end{array}$ & $\begin{array}{l}\text { Local values } \pm 0.6 \text { to } \pm 1.1 \mathrm{mrad} \\
\text { RMS values: } \pm 0.1 \mathrm{mrad}\end{array}$ & $\begin{array}{l}\text { RMS: Global uncertainty via Monte } \\
\text { Carlo approach, QFly [33] }\end{array}$ \\
\hline Receiver position & $\begin{array}{l}\text { Airborne photogrammetry, values } \\
\text { from [66] }\end{array}$ & $<1.5 \mathrm{~mm}$ for each direction & $\begin{array}{c}u_{\mathrm{Abs}} \text { for } \mathrm{X} \text { and Z directions, } \\
\text { QFly [66] }\end{array}$ \\
\hline \multirow{2}{*}{$\begin{array}{l}\text { Receiver glass temperature/ } \\
\text { piping temperature }\end{array}$} & $\begin{array}{c}\text { Airborne infrared camera, } \\
\text { e.g., [67] }\end{array}$ & $\begin{array}{c}<3 \mathrm{~K} \text { compared to resistance } \\
\text { thermometers }\end{array}$ & $\begin{array}{c}\text { Airborne approach only possible at } \\
\text { wind speeds }<6-8 \mathrm{~m} / \mathrm{s} \text { [67] }\end{array}$ \\
\hline & $\begin{array}{c}\text { Vehicle-mounted infrared camera, } \\
\text { e.g., [63] }\end{array}$ & $\begin{array}{l}<3 \mathrm{~K} @ 1 \text { to } 6 \mathrm{~m} / \mathrm{s} \text { wind speed, } \\
\text { compared to thermocouple }\end{array}$ & $\begin{array}{l}\text { Temperature difference of ITR } \\
\text { system [63] }\end{array}$ \\
\hline \multirow{2}{*}{ Cleanliness } & $\begin{array}{l}\text { Continuous cleanliness } \\
\text { measurement with tracked } \\
\text { Pyrheliometer, e.g., TraCS }\end{array}$ & $\pm 1.8 \%(1 \sigma)$ & $\begin{array}{c}\text { Combined standard uncertainty } u_{\xi} \\
\text { for minute value of } \\
\text { cleanliness [28] }\end{array}$ \\
\hline & $\begin{array}{l}\text { Continuous cleanliness } \\
\text { measurement with mirror } \\
\text { samples, e.g., AVUS }\end{array}$ & - & $\begin{array}{c}\text { In Heimsath et al. [70] compared to } \\
\text { D\&S Reflectometer }\end{array}$ \\
\hline \multirow{2}{*}{$\begin{array}{c}\text { DNI Maps } \\
\text { (spatial DNI forecast) }\end{array}$} & All sky imager & $\begin{array}{l}\text { In the range from approx. } \\
-50 \mathrm{~W} / \mathrm{m}^{2} \text { and }+30 \mathrm{~W} / \mathrm{m}^{2} \text { (lead } \\
\text { time } 0 \mathrm{~min} \text { ) to }-260 \mathrm{~W} / \mathrm{m}^{2} \text { and } \\
\left.+120 \mathrm{~W} / \mathrm{m}^{2} \text { (lead time } 15 \mathrm{~min}\right)\end{array}$ & $\begin{array}{c}\text { Site specific uncertainty according } \\
\text { to occurrence of DNI class and lead } \\
\text { time [82] }\end{array}$ \\
\hline & Shadow camera & Between $4.2 \%$ and $16.7 \%$ (RMSE) & $\begin{array}{l}\text { For DNI maps without forecast, } \\
\text { uncertainty depends on cloud } \\
\text { occurrence [73] }\end{array}$ \\
\hline \multirow[t]{2}{*}{ Specific heat capacity } & $\begin{array}{l}\text { Inline measurement system } \\
\text { KONTAS-CP [81] }\end{array}$ & $<1.2 \%$ & $\begin{array}{l}\text { Deviation to Differential Scanning } \\
\text { Calorimetry (DSC) for } \\
\mathrm{T}<270^{\circ} \mathrm{C}[83]\end{array}$ \\
\hline & $\begin{array}{c}\text { Calorimeter for solar thermal } \\
\text { testing loops [80] }\end{array}$ & 3 to $4 \%$ & Upper limit for accuracy [79] \\
\hline
\end{tabular}

\section{Discussion and Outlook}

The first parabolic trough fields have been operational since the 1980s, more recent plants since the beginning of this century. During this time, a lot of experience and improvement related to the measurement instrumentation has been made. Most of the instruments installed today are needed to fulfill a certain control task in the plant. The selection of the number of sensors, their accuracy and also data logging is based on real control needs. The different control systems in the solar field try to reach, e.g., a high focus of each collector and a loop outlet temperature close to the setpoint. At the same time, the control system needs to stay within the limits for a safe and reliable operation. The requirements for the measurement sensors, in order to reach a high solar field performance, is not just a question of low measurement uncertainty. Instrument reliability in harsh environments, experience with the used sensor and costs are just a few other influences on the decision for a certain measurement instrumentation.

With the capabilities of data-driven monitoring approaches, available instrumentation is gaining additional attention because it can be used to deduce further information on the current status of the system. However, the direct usage of sensor signals is limited. Either the built-in instrumentation may not have the required accuracy to detect minor deviations in component performance, or relevant sensors for such a kind of evaluation are missing. For example, the precise mass flow in the loop is usually not measured to derive the energy balance over a collector. For cost reasons, many signals are only processed locally in the field control units but not transmitted nor logged in a central unit. Despite such hurdles, 
the existing instrumentation, together with selected additional sensors, offers opportunities for improved solar field monitoring.

The aim of this paper is to give an overview of the typically installed measurement equipment in parabolic trough solar fields and their accuracy. The required instruments for a regular field operation are temperature and pressure sensors, mass or volume flow meters and tracking sensors. Additionally, meteorological instrumentation, such as pyrheliometers, pyranometers or rotating shadow band irradiometers or other sunshape measurement devices to derive the available solar resource and the sunshape. This solar specific instrumentation is combined with standard meteorological instrumentation to measure the dry bulb temperature, atmospheric pressure, relative humidity, wind (gust) speed and precipitation. These continuously measuring sensors are complemented from time to time with specific measurements in order to maintain the solar field performance at a high level. This is achieved with infrared thermography to qualify the condition of the receivers, mirror cleanliness measurements to estimate the soiling level or the collector shape, its deformation with forces and slope measurements based on photogrammetry, deflectometry or laser scanning techniques to check the collector geometry. Heat transfer fluid analyses to measure the hydrogen content and the specific heat capacity are usually performed periodically. In recent years, advanced measurement techniques have been developed. Their main purpose is to further optimize the solar field operation. They allow much more data to be generated, especially with higher spatial resolution. Examples are vehicle-mounted or airborne camera systems that can observe large areas of the solar field. They are equipped with powerful image processing features to derive spatially resolved maps of slope deviation, mirror cleanliness, receiver glass envelope temperatures, broken mirrors, etc. All sky imager or shadow cameras deliver highly resolved DNI maps for nowcasting. In summary, the already available and optional measurement equipment will promote new field monitoring techniques in the upcoming decade. The present paper provides a sound reference for engineers working on such advanced monitoring techniques.

Future approaches, relying on big data, are advanced condition monitoring, predictive maintenance and optimized control and operation strategies. Progress in condition monitoring has the aim of merging different data streams within the power plant and maximize the information about the field. Built-in instrumentation and recent additional measurement techniques, together with artificial intelligence (AI), are able to model new data streams, which contain directly useful information for the operator. One example for this is the application of anomaly detection in the solar field. Anomaly detection algorithms with the background knowledge of historical data are able to detect unusual behavior in every data stream from the field all at the same time. Connections between different data streams can identify anomalies in a spatial and temporal context. These fingerprints of certain failures can be used for predictive maintenance applications in order to identify defective components before the system has unexpected downtime. Further optimization in operation and control strategy needs, e.g., spatially distributed forecasts about irradiance, together with the information about the current plant condition. These advanced strategies are able to further increase the efficiency, as well as to reduce the harmful conditions, of the component and, therefore, extend its lifetime.

Author Contributions: Conceptualization, A.B., T.H. and M.R.; methodology, A.B.; validation, A.B., T.H. and M.R.; formal analysis, A.B.; investigation, A.B.; writing-original draft preparation, A.B.; writing-review and editing, A.B., T.H. and M.R.; visualization, A.B.; supervision, T.H., M.R. and R.P.-P.; funding acquisition, T.H. All authors have read and agreed to the published version of the manuscript.

Funding: This research received no external funding.

Institutional Review Board Statement: Not applicable.

Informed Consent Statement: Not applicable. 
Data Availability Statement: Not applicable.

Acknowledgments: The authors want to thank the numerous people from industry and science who contributed with their knowledge and experience from practice.

Conflicts of Interest: The authors declare no conflict of interest.

List of Abbreviations Including Units and Nomenclature

\begin{tabular}{|c|c|}
\hline AI & Artificial intelligence \\
\hline ASI & All sky imager \\
\hline AVUS & Automated In situ Measurement of Contamination Quotas and Spectrums \\
\hline CSP & Concentrated solar power \\
\hline DHI & Diffuse horizontal irradiance $\left(\mathrm{W} / \mathrm{m}^{2}\right)$ \\
\hline DLR & German Aerospace Center \\
\hline DNI & Direct normal irradiance $\left(\mathrm{W} / \mathrm{m}^{2}\right)$ \\
\hline DOE & US Department of Energy \\
\hline DSC & Differential Scanning Calorimetry \\
\hline GHI & Global horizontal irradiance $\left(\mathrm{W} / \mathrm{m}^{2}\right)$ \\
\hline GUM & Guide to the expression of uncertainty in measurement \\
\hline HCE & Heat collecting element \\
\hline HTF & Heat transfer fluid \\
\hline IR & Infrared \\
\hline ITR & Inspection Receiver Tubes \\
\hline KONTAS CP & Concentrator test facility Almería Spain with calorimeter unit \\
\hline LBL & Lawrence Berkeley Laboratory \\
\hline LCOE & Levelized cost of electricity \\
\hline LED & Light emitting diode \\
\hline PV & Photovoltaic \\
\hline RMS & Root mean square \\
\hline RMSE & Root mean square error \\
\hline RSI & Rotating shadow band irradiometer \\
\hline SAM & Sun and Aureole Measurement system \\
\hline SCA & Solar collector assembly \\
\hline SPA & Solar Position Algorithm \\
\hline TARMES & Trough Absorber Reflection Measurement System \\
\hline TOP & Theoretical overlay photographic \\
\hline TraCS & Tracking Cleanliness Sensor \\
\hline UAV & Unmanned aerial vehicle \\
\hline VSHOT & Video Scanning Hartmann Optical Test System \\
\hline
\end{tabular}

\section{References}

1. NREL. Concentrating Solar Power Projects. National Renewable Energy Laboratory (NREL). Available online: https://solarpaces. nrel.gov/ (accessed on 18 January 2021).

2. Murphy, C.; Sun, Y.; Cole, W.; Maclaurin, G.; Turchi, C.; Mehos, M. The Potential Role of Concentrating Solar Power within the Context of DOE's 2030 Solar Cost Targets; NREL: Golden, CO, USA, 2019. [CrossRef]

3. Morris, A.S.; Langari, R. Measurement and Instrumentation; Elsevier Science \& Technology: Saint Louis, MO, USA, 2012; ISBN 9780123819604

4. Joint Committee for Guides in Metrology (JCGM). Evaluation of Measurement Data-Guide to the Expression of Uncertainty in Measurement. 2008. Available online: https://www.bipm.org/utils/common/documents/jcgm/JCGM_100_2008_E.pdf (accessed on 18 January 2021).

5. Boyes, W. Instrumentation Reference Book; Elsevier Science \& Technology: Amsterdam, The Netherlands, 2010; ISBN 9780750683081.

6. Ding, W.; Bonk, A.; Bauer, T. Corrosion behavior of metallic alloys in molten chloride salts for thermal energy storage in concentrated solar power plants: A review. Front. Chem. Sci. Eng. 2018, 12, 564-576. [CrossRef]

7. Nouri, B.; Röger, M.; Janotte, N.; Hilgert, C. Characterization and Corrections for Clamp-On Fluid Temperature Measurements in Turbulent Flows. J. Thermal Sci. Eng. Appl. 2018, 10, 031011. [CrossRef]

8. DIN German Institute for Standardization. Industrial Platinum Resistance Thermometers and Platinum Temperature Sensors (IEC 60751:2008); German Version EN 60751:2008; Beuth Verlag GmbH: Berlin, Germany, 2009.

9. DIN German Institute for Standardization. Thermocouples_Part. 1: EMF Specifications and Tolerances (IEC 60584-1:2013); German Version EN 60584-1:2013; Beuth Verlag GmbH: Berlin, Germany, 2014. [CrossRef]

10. Bentley, J.P. Temperature sensor characteristics and measurement system design. J. Phys. E Sci. Instrum. 1984, 17, 430-439. [CrossRef]

11. Deutsche Akkreditierungsstelle (DAkkS). Kalibrierung von Widerstandsthermometern; Deutsche Akkreditierungsstelle (DAkkS): Berlin, Germany, 2010. 
12. Janotte, N. Requirements for Representative Acceptance Tests for the Prediction of the Annual Yield of Parabolic Trough Solar Fields; Shaker Verlag GmbH: Düren, Germany, 2012; ISBN 978-3-8440-1565-2.

13. Baker, R.C. Flow Measurement Handbook: Industrial Designs, Operating Principles, Performance, and Applications; Cambridge University Press: Cambridge, UK, 2000; ISBN 0-521-48010-8.

14. Cairney, W.D. Typical flow measurement problems and their solution in the electricity supply industry. Flow Meas. Instrum. 1991, 2, 217-223. [CrossRef]

15. CNRS. R12.10 Report on Mass Flow Measurement and Calibration Procedures. Available online: http://sfera.sollab.eu/ downloads/JRA/WP12/Delivrable_R12.10_Report_on_mass_flow_measurement_and_calibration_procedures.pdf (accessed on 1 September 2021).

16. Janotte, N.; Wilbert, S.; Sallaberry, F.; Schroedter-Homscheidt, M.; Ramirez, L. 2-Principles of CSP performance assessment. In The Performance of Concentrated Solar Power (CSP) Systems; Heller, P., Ed.; Woodhead Publishing: Sawston, UK, 2017 ; pp. 31-64.

17. Lee, C.-Y.; Chou, P.-C.; Chiang, C.-M.; Lin, C.-F. Sun Tracking Systems: A Review. Sensors 2009, 9, 3875-3890. [CrossRef] [PubMed]

18. Michalsky, J.J. The Astronomical Almanac's algorithm for approximate solar position (1950-2050). Sol. Energy 1988, 40, 227-235. [CrossRef]

19. Reda, I.; Andreas, A. Solar Position Algorithm for Solar Radiation Applications (Revised); National Renewable Energy Laboratory (NREL): Golden, CO, USA, 2008. [CrossRef]

20. Shuman, F.; Boys, C.V. Sun-Boiler. US1240890A, 25 September 1917.

21. Solar Millennium AG. Die Parabolrinnen-Kraftwerke Andasol 1 bis 3. Die Größten Solarkraftwerke der Welt; Premiere der Technologie in Europa; Solar Millennium AG: Erlangen, Germany, 2008.

22. Price, H.; Forristall, R.; Wendelin, T.; Lewandowski, A.; Moss, T.; Gummo, C. Field Survey of Parabolic Trough Receiver Thermal Performance. In Proceedings of the ASME International Solar Energy Conference, Denver, CO, USA, 8-13 July 2006.

23. Caron, S.; Röger, M. In-situ heat loss measurements of parabolic trough receivers based on transient infrared thermography. Sol. Energy 2016, 135, 10. [CrossRef]

24. Minkina, W.; Dudzik, S. Uncertainties of Measurements in Infrared Thermography. In Infrared Thermography; Wiley: Hoboken, NJ, USA, 2009.

25. Kearney, D. Utility-Scale Parabolic Trough Solar Systems: Performance Acceptance Test Guidelines, April 2009-December 2010; National Renewable Energy Laboratory (NREL): Golden, CO, USA, 2011. [CrossRef]

26. Cohen, G.E.; Kearney, D.W.; Kolb, G.J. Final Report on the Operation and Maintenance Improvement Program for Concentrating Solar Power Plants; Sandia National Laboratories (SNL): Albuquerque, NM, USA; Livermore, CA, USA, 1999. [CrossRef]

27. Fernández-García, A.; Sutter, F.; Fernández-Reche, J.; Lüpfert, E. 3-Mirrors. In The Performance of Concentrated Solar Power (CSP) Systems; Heller, P., Ed.; Woodhead Publishing: Sawston, UK, 2017; pp. 67-98.

28. Wolfertstetter, F.; Pottler, K.; Alami Merrouni, A.; Mezrhab, A.; Pitz-Paal, R. A Novel method for Automatic Real-Time Monitoring of Mirror Soiling Rates. In Proceedings of the SolarPACES Conference, Marrakesch, Morocco, 11-14 September 2012 ; p. 9.

29. Zhu, G.; Kearney, D.; Mehos, M. On characterization and measurement of average solar field mirror reflectance in utility-scale concentrating solar power plants. Sol. Energy 2014, 99, 185-202. [CrossRef]

30. Wolfertstetter, F. Auswirkungen von Verschmutzung auf Konzentrierende Solarthermische Kraftwerke. Ph.D. Thesis, RWTH Aachen, Aachen, Germany, 2016.

31. Ulmer, S.; Pottler, K.; Lüpfert, E.; Röger, M. Measurement Techniques for the Optical Quality Assessment of Parabolic Trough Collector Fields in Commercial Solar Power Plants. In Proceedings of the Energy Sustainability, Long Beach, CA, USA, 27-30 July 2007; pp. 1085-1091.

32. Ulmer, S.; Heinz, B.; Pottler, K.; Lüpfert, E. Slope Error Measurements of Parabolic Troughs Using the Reflected Image of the Absorber Tube. J. Sol. Energy Eng. 2009, 131, 011014. [CrossRef]

33. Prahl, C.; Stanicki, B.; Hilgert, C.; Ulmer, S.; Röger, M. Airborne shape measurement of parabolic trough collector fields. Sol. Energy 2013, 91, 68-78. [CrossRef]

34. Wendelin, T.; May, K.; Gee, R. Video Scanning Hartmann Optical Testing of State-of-the-Art Parabolic Trough Concentrators: Preprint. In Proceedings of the Solar 2006 Conference (ISEC' 06), Denver, CO, USA, 8-13 July 2006.

35. Diver, R.B.; Moss, T.A. Practical Field Alignment of Parabolic Trough Solar Concentrators. J. Sol. Energy Eng. 2006, 129, 153-159. [CrossRef]

36. Wood, R.L. Distant-Observer Techniques for Verification of Solar-Concentrator Optical Geometry; Lawrence Livermore National Lab.: Livermore, CA, USA, 1981.

37. Shortis, M.R.; Johnston, G.H.G. Photogrammetry: An Available Surface Characterization Tool for Solar Concentrators, Part I: Measurements of Surfaces. J. Sol. Energy Eng. 1996, 118, 146-150. [CrossRef]

38. Pottler, K.; Lüpfert, E.; Johnston, G.H.G.; Shortis, M.R. Photogrammetry: A Powerful Tool for Geometric Analysis of Solar Concentrators and Their Components. J. Sol. Energy Eng. 2005, 127, 94-101. [CrossRef]

39. Meola, C. Infrared Thermography Recent Advances and Future Trends; Bentham Science: Sharjah, United Arab Emirates, 2012; ISBN 9781608051434.

40. Infratec. Technical Specifications ImageIR 8300. Available online: https://www.infratec-infrared.com/thermography/infraredcamera/imageir-8300/ (accessed on 18 November 2020). 
41. Lovegrove, K. Concentrating Solar Power Technology: Principles, Developments and Applications; Elsevier Science \& Technology: Cambridge, UK, 2012; ISBN 9780857096173.

42. Wolfertstetter, F.; Pottler, K.; Geuder, N.; Affolter, R.; Merrouni, A.A.; Mezrhab, A.; Pitz-Paal, R. Monitoring of Mirror and Sensor Soiling with TraCS for Improved Quality of Ground based Irradiance Measurements. Energy Proc. 2014, 49, 2422-2432. [CrossRef]

43. Pape, B.; Batlles, J.; Geuder, N.; Pinero, R.Z.; Adan, F.; Pulvermüller, B. Soiling impact and correction formulas in solar measurements for CSP projects. In Proceedings of the SolarPACES Conference, Berlin, Germany, 15-18 September 2009.

44. Schwandt, M.; Radtke, J.; Petersen, A.; Heimsath, A.; Meyer, R. Soiling impact on direct normal irradiation measurements. In Proceedings of the SolarPACES Conference, Daegu, Korea, 1-4 October 2019.

45. Wilbert, S. Determination of Circumsolar Radiation and Its Effect on Concentrating Solar Power. Ph.D. Thesis, RWTH Aachen, Aachen, Germany, 2014.

46. Grether, D.; Nelson, J.; Wahlig, M. Measurement of circumsolar radiation. In Proceedings of the 19th Annual Technical Symposium of the Society of Photo-Optical Instrumentation Engineers, San Diego, CA, USA, August 1975.

47. Neumann, A.; Von der Au, B.; Heller, P. Measurement of Circumsolar Radiation at the Plataforma Solar de Almería (Spain) and at DLR (Germany). In Proceedings of the ASME International Solar Energy Conference, Albuquerque, NM, USA, $14-17$ June 1998.

48. Wilbert, S.; Pitz-Paal, R.; Jaus, J. Comparison of measurement techniques for the determination of circumsolar irradiance. AIP Conf. Proc. 2013, 1556, 162-167. [CrossRef]

49. Schrott, S.; Schmidt, T.; Hornung, T.; Nitz, P. Scientific system for high-resolution measurement of the circumsolar radiation. In Proceedings of the 10th International Conference on Concentrator Photovoltaic Systems, Albuquerque, NM, USA, 7-9 April 2014.

50. Wilbert, S.; Röger, M.; Csambor, J.; Breitbach, M.; Klinger, F.; Nouri, B.; Hanrieder, N.; Wolfertstetter, F.; Schüler, D.; Shaswattam, S.; et al. Sunshape measurements with conventional rotating shadowband irradiometers. AIP Conf. Proc. 2018, $2033,190016$. [CrossRef]

51. Wilbert, S.; Kleindiek, S.; Nouri, B.; Geuder, N.; Habte, A.; Schwandt, M.; Vignola, F. Uncertainty of rotating shadowband irradiometers and Si-pyranometers including the spectral irradiance error. In Proceedings of the SolarPACES Conference, Cape Town, South Africa, 13-16 October 2015; p. 150009.

52. Wilbert, S.; Pitz-Paal, R.; Jaus, J. Circumsolar Radiation and Beam Irradiance Measurements for Focusing Collectors. In Proceedings of the ES1002: Cost Wire Workshop, Köln-Porz, Germany, May 2012.

53. Burkholder, F.; Kutscher, C. Heat Loss Testing of Schott's 2008 PTR70 Parabolic Trough Receiver; National Renewable Energy Laboratory (NREL): Golden, CO, USA, 2009. [CrossRef]

54. World Meteorological Organization. Guide to Meteorological Instruments and Methods of Observation; World Meteorological Organization: Genewa, Switzerland, 2014; ISBN 978-92-63-10008-5.

55. Price, H. A parabolic trough solar power plant simulation model. In Proceedings of the ASME 2003 International Solar Energy Conference, Kohala Coast, HI, USA, 15-18 March 2003; pp. 665-673.

56. Wolfertstetter, F.; Wilbert, S.; Terhag, F.; Hanrieder, N.; Fernandez-García, A.; Sansom, C.; King, P.; Zarzalejo, L.; Ghennioui, A Modelling the soiling rate: Dependencies on meteorological parameters. AIP Conf. Proc. 2019, 2126, 190018. [CrossRef]

57. Jung, C. Thermal Stability of Used Eutectic Mixture of Biphenyl and Diphenyl Ether. In Proceedings of the SolarPACES Conference, online, 27 September-1 October 2021.

58. Jung, C.; Senholdt, M.; Spenke, C.; Schmidt, T.; Ulmer, S. Hydrogen monitoring in the heat transfer fluid of parabolic trough plants. In Proceedings of the SolarPACES Conference, Casablanca, Morocco, 2-5 October 2018; p. 080004.

59. Jung, C.; Nietsch, A. Precise Heat Capacity Determination of Organic Heat Transfer Fluids. In Proceedings of the Summer School of Calorimetry, Lyon, France, 14-19 June 2014.

60. Schaffer, E. Silicone-based Heat Transfer Fluids-Overcoming the Thermal Limits of Parabolic Trough Plants with Bankable Systems. In Proceedings of the SolarPACES Conference, online, 27 September-1 October 2021.

61. Gomez, J.C.; Glatzmaier, G.C.; Mehos, M. Heat Capacity Uncertainty Calculation for the Eutectic Mixture of Biphenyl/Diphenyl Ether Used as Heat Transfer Fluid. In Proceedings of the SolarPACES, Marrakech, Morocco, 11-14 September 2012.

62. Röger, M.; Prahl, C.; Pernpeintner, J.; Sutter, F. 7-New methods and instruments for performance and durability assessment. In The Performance of Concentrated Solar Power (CSP) Systems; Heller, P., Ed.; Woodhead Publishing: Sawston, UK, 2017 ; pp. $205-252$.

63. Jalón, A.G.D.; Pérez, D.; Benito, P.; Zaversky, F. Inspection Receiver Tubes Device for CSP Plants. Energy Proc. 2015, 69, 1868-1876. [CrossRef]

64. Olano, X.; De Jalón, A.G.; Pérez, D.; Barberena, J.G.; López, J.; Gastón, M. Outcomes and features of the inspection of receiver tubes (ITR) system for improved O\&M in parabolic trough plants. In Proceedings of the SolarPACES Conference, Santiago, Chile, 26-29 September 2018.

65. Jorgensen, G.; Burkholder, F.; Gray, A.; Wendelin, T. Assess the Efficacy of an Aerial Distant Observer Tool Capable of Rapid Analysis of Large Sections of Collector Fields; National Renewable Energy Laboratory (NREL): Golden, CO, USA, 2009.

66. Prahl, C.; Röger, M.; Stanicki, B.; Hilgert, C. Absorber tube displacement in parabolic trough collectors-A review and presentation of an airborne measurement approach. Sol. Energy 2017, 157, 692-706. [CrossRef]

67. Prahl, C.; Röger, M.; Hilgert, C. Air-borne shape measurement of parabolic trough collector fields. In Proceedings of the SolarPACES Conference, Abu Dhabi, United Arab Emirates, 11-14 October 2016.

68. Wolfertstetter, F.; Fonk, R.; Prahl, C.; Röger, M.; Wilbert, S.; Fernández-Reche, J. Airborne soiling measurements of entire solar fields with Qfly. AIP Conf. Proc. 2020, 2303, 100008. [CrossRef] 
69. Röger, M.; Prahl, C.; Algner, N.; Reinalter, W. Regelmäßige Vermessung thermischer und optischer Komponenten in Parabolrinnenfeldern. In Proceedings of the 21 Kölner Sonnenkolloquium 2018, Köln-Porz, Germany, 4 July 2018.

70. Heimsath, A.; Schmidt, T.; Steinmetz, J.; Reetz, C.; Schwandt, M.; Meyer, R.; Nitz, P. Automated monitoring of soiling with AVUS instrument for improved solar site assessment. In Proceedings of the SolarPACES Conference, Santiago, Chile, 26-29 September 2017.

71. Heimsath, A.; Schmidt, T.; Rohani, S.; Haack, L.; Meyer, R.; Steinmetz, J.; Nitz, P. Monitoring of soiling with the AVUS instrument-Technical and economic assessment. In Proceedings of the SolarPACES, Casablanca, Morocco, 2-5 October 2018; p. 190007.

72. Nouri, B.; Kuhn, P.M.; Wilbert, S.; Prahl, C.; Pitz-Paal, R.; Blanc, P.; Schmidt, T.; Yasser, Z.; Ramirez, L.; Heinemann, D. Nowcasting of DNI Maps for the Solar Field Based on Voxel Carving and Individual 3D Cloud Objects from All Sky Images. In Proceedings of the SolarPACES Conference, Santiago, Chile, 26-29 September 2017.

73. Kuhn, P.M.; Wilbert, S.; Prahl, C.; Schüler, D.; Haase, T.; Hirsch, T.; Wittmann, M.; Ramirez, L.; Zarzalejo, L.F.; Meyer, A.; et al. Shadow camera system for the generation of solar irradiance maps. Sol. Energy 2017, 157, 157-170. [CrossRef]

74. Nouri, B.; Noureldin, K.; Schlichting, T.; Wilbert, S.; Hirsch, T.; Schroedter-Homscheidt, M.; Kuhn, P.; Kazantzidis, A.; Zarzalejo, L.F.; Blanc, P.; et al. A Way to Increase Parabolic Trough Plant Yield by Roughly 2\% Using All Sky Imager Derived DNI Maps. In Proceedings of the SolarPaces Conference, Daegu, Korea, 1-4 October 2019.

75. Nouri, B.; Noureldin, K.; Schlichting, T.; Wilbert, S.; Hirsch, T.; Schroedter-Homscheidt, M.; Kuhn, P.; Kazantzidis, A.; Zarzalejo, L.F.; Blanc, P.; et al. Optimization of parabolic trough power plant operations in variable irradiance conditions using all sky imagers. Sol. Energy 2020, 198, 434-453. [CrossRef]

76. Noureldin, K.; Hirsch, T.; Pitz-Paal, R. VSF-An Opportunity to Optimize Transient Processes in Line-Focus CSP Power Plants. In Proceedings of the SolarPACES Conference, Abu Dhabi, United Arab Emirates, 11-14 October 2016.

77. Noureldin, K.; Hirsch, T.; Pitz-Paal, R. Virtual Solar Field-Validation of a detailed transient simulation tool for line focus STE fields with single phase heat transfer fluid. Sol. Energy 2017, 146, 131-140. [CrossRef]

78. Janotte, N.; Lüpfert, E.; Pitz-Paal, R.; Pottler, K.; Eck, M.; Zarza, E.; Riffelmann, K.-J. Influence of Measurement Equipment on the Uncertainty of Performance Data from Test Loops for Concentrating Solar Collectors. J. Sol. Energy Eng. 2010, 132. [CrossRef]

79. Marchã, J.; Osório, T.; Pereira, M.C.; Horta, P. Development and Test Results of a Calorimetric Technique for Solar Thermal Testing Loops, Enabling Mass Flow and Cp Measurements Independent from Fluid Properties of the HTF Used. Energy Proc. 2014, 49, 2125-2134. [CrossRef]

80. Collares-Pereira, M.; Duque, J.; Saraiva, C.; Rego-Teixeira, A. A calorimeter for solar thermal collector testing. Sol. Energy 1981, 27, 581-582. [CrossRef]

81. Hilgert, C.; Bern, G.; Röger, M. Kontas-CP-Flow Through Calorimeter for Online Heat Capactiy Measurement of Thermal Oils in CSP Application. In Proceedings of the SolarPACES Conference, Marrakesch, Morocco, 11-14 September 2012.

82. Nouri, B.; Wilbert, S.; Kuhn, P.M.; Hanrieder, N.; Schroedter-Homscheidt, M.; Kazantzidis, A.; Zarzalejo, L.F.; Blanc, P.; Kumar, S.; Goswami, N.; et al. Real-Time Uncertainty Specification of All Sky Imager Derived Irradiance Nowcasts. Remote. Sens. 2019, 11, 1059. [CrossRef]

83. Hilgert, C.; Howar, F.; Röger, M. Flow through calorimeter to measure fluid heat capacity in CSP applications. Sol. Energy 2019, 194, 804-814. [CrossRef] 